Review

\title{
Breath Analysis as a Potential and Non-Invasive Frontier in Disease Diagnosis: An Overview
}

\section{Jorge Pereira ${ }^{1, *}$, Priscilla Porto-Figueira ${ }^{1}$, Carina Cavaco ${ }^{1}$, Khushman Taunk ${ }^{2}$, Srikanth Rapole $^{2}$, Rahul Dhakne ${ }^{3}$, Hampapathalu Nagarajaram ${ }^{3}$ and José S. Câmara ${ }^{1,4}$}

1 CQM — Centro de Química da Madeira, Universidade da Madeira, Campus Universitário da Penteada, Funchal 9000-390, Portugal; E-Mails: priscillaportofigueira@gmail.com (P.P.-F.); carina-cavaco@hotmail.com (C.C.); jsc@uma.pt (J.S.C.)

2 Proteomics Lab, National Centre for Cell Science, Ganeshkhind, Pune 411007, India; E-Mails: khushmanlord@gmail.com (K.T.); rsrikanth@nccs.res.in (S.R.)

3 Laboratory of Computational Biology, Centre for DNA Fingerprinting \& Diagnostics, Hyderabad, Andhra Pradesh 500 001, India; E-Mails: rahuldhakne@cdfd.org.in (R.D.); han@cdfd.org.in (H.N.)

4 Centro de Ciências Exatas e da Engenharia da Universidade da Madeira, Campus Universitário da Penteada, Funchal 9000-390, Portugal

* Author to whom correspondence should be addressed; E-Mail: jamp@uma.pt; Tel.: +351-291-705-131; Fax: +351-291-705-149.

Academic Editor: Peter Meikle

Received: 8 July 2014; / Accepted: 12 December 2014 / Published: 9 January 2015

\begin{abstract}
Currently, a small number of diseases, particularly cardiovascular (CVDs), oncologic (ODs), neurodegenerative (NDDs), chronic respiratory diseases, as well as diabetes, form a severe burden to most of the countries worldwide. Hence, there is an urgent need for development of efficient diagnostic tools, particularly those enabling reliable detection of diseases, at their early stages, preferably using non-invasive approaches. Breath analysis is a non-invasive approach relying only on the characterisation of volatile composition of the exhaled breath (EB) that in turn reflects the volatile composition of the bloodstream and airways and therefore the status and condition of the whole organism metabolism. Advanced sampling procedures (solid-phase and needle traps microextraction) coupled with modern analytical technologies (proton transfer reaction mass spectrometry, selected ion flow tube mass spectrometry, ion mobility spectrometry, e-noses, etc.) allow the characterisation of EB composition to an unprecedented level. However, a key challenge in
\end{abstract}


EB analysis is the proper statistical analysis and interpretation of the large and heterogeneous datasets obtained from EB research. There is no standard statistical framework/protocol yet available in literature that can be used for EB data analysis towards discovery of biomarkers for use in a typical clinical setup. Nevertheless, EB analysis has immense potential towards development of biomarkers for the early disease diagnosis of diseases.

Keywords: Exhaled Breath (EB) analysis; Disease diagnosis; volatile organic compounds (VOCs), volatile fingerprint, breath analysis based disease diagnosis (BADD)

\section{Introduction}

Non-communicable diseases, such as cardiovascular (CVDs), oncologic (ODs), neurodegenerative (NDDs), and chronic respiratory diseases, are the major causes of death in the developed countries [1]. They are also becoming highly prevalent in the developing countries due to changing lifestyles. It is estimated that by the year 2020, seven out of 10 deaths in developing countries and $80 \%$ of the global disease burden would be caused by non-communicable diseases [1]. For example, Diabetes is a major concern for the developing countries, as its incidence is projected to triplicate from 84 to 228 million cases during 2000-2030 period [2]. Taking together with the high incidence of infectious diseases, such as AIDS, malaria and different haemorrhagic viral infections, there is a double disease burden on developing countries [3]. There are two key contributing factors for this highly negative prognosis. They are: (a) Late diagnosis, usually performed using invasive and expensive procedures, when the diseases have already reached a life-threatening stage and (b) the critical lack of medical and laboratorial infrastructures [4]. Hence, there is an urgent need for development of new efficient diagnosis tools, particularly, those which reliably detect diseases at their early stages. Such technologies have to be cheap, reliable, rugged and portable, otherwise they may not be within the reach of most of the people living in the developing countries [3]. From this standpoint breath analysis based disease diagnosis (BADD) looks very promising and attractive. In this review, we focus on BADD discussing on the current trends and innovations from sampling procedure to the final data analysis and diagnosis opportunities. Regarding the EB volatile composition, we discuss the metabolic profiles of the most interesting volatiles and present a few selected examples of putative biomarkers. Finally, we will also discuss the data analysis processes followed in literature and their relevance in the light of the complexity of data generated from EB studies.

\section{Exhaled Breath (EB) Analysis}

Breath analysis is possibly one of the oldest forms of diagnosis. Its usage for disease diagnostics dates back to ancient Greeks where physicians used EB to diagnose different diseases $[5,6]$. Breath odours allow correct associations to certain diseases. For example, the sweet smell of diabetic ketoacidosis, the rancid odour of $C$. difficile stools [6], the fishy smell of breath associated to liver illness, the urine-like odour of kidney disease, the grapes flavour of Pseudomonas infections [5,7] or the sewer smell of the breath of patients with lung abscesses, caused by the proliferation of anaerobic bacteria [8-11]. The 
reason behind this capability is certainly the powerful human olfactory system that Bushdid et al. [12] recently demonstrated to be able to discriminate at least 1 trillion different olfactory stimuli. EB composition reflects the volatile composition of the bloodstream, and its composition can be correlated with the arterial concentration of the same analytes, although we have to consider that some volatile compounds are originated in the airways, not being present in the blood (as nitric oxide, for instance) [13]. Regardless of their origin, it would be very difficult to detect most of the volatiles directly from blood samples [14]. EB is mainly composed of nitrogen $\left(\mathrm{N}_{2}\right)$, oxygen $\left(\mathrm{O}_{2}\right)$, carbon dioxide $\left(\mathrm{CO}_{2}\right)$, water vapour and inert gases. $\mathrm{O}_{2}$ and $\mathrm{CO}_{2}$ diffuse passively between blood and breath according to their concentration gradients across the alveolar-capillary junction, dragging together thousands of other very low abundant volatile organic compounds (VOCs), as long as they exhibit significant vapour pressures [15]. These VOCs, estimated in over 3000, account for less than 100 parts per million (ppm) of the total breath volume [13,16,17], although part of them, as acetone, isoprene and propanol, are more abundant, existing in the ppm to sub ppm range, while ketones, aldehydes and pentane, for instance, occur at even lower concentrations, at the parts per billion (ppb) to parts per trillion (ppt) levels [18-21]. It is precisely the combination of these VOCs that define the "smell" of EB. Many of them are systemic or endogenous, being produced in physiological processes, but the metabolic routes behind their production are known only for a very limited number of VOCs (reviewed in [13]). Other VOCs are exogenous and result from external contamination through the inhaled air or ingested foods or drinks. These are considered as pollution or background noise [22]. Unfortunately, this seems to be the case for most VOCs. Phillips et al. [10] analysed the EB from 50 normal individuals and processed the data obtained considering that only the VOCs with positive alveolar gradient (concentration higher in breath than in air) are more likely to be endogenous and not inhaled from external environment through the lung. They found that only half of the 340 VOCs identified fulfilled this condition. Moreover, they also reported a broad sample variation, because only 27 of these endogenous VOCs were present in all individuals [10]. This result is illustrative of the complexity of the EB samples and the existence of many contaminants originated by the ambient surroundings. In addition there are also other problems related with the subject or the analytical approach selected, as discussed by van de Kant et al. [23] for VOCs analysis in pulmonary diseases. Regarding the environmental influence, besides the contamination with ambient VOCs, the abundance of $\mathrm{CO}_{2}$ and water vapour in exhaled air, is particularly challenging as water condensation interferes with the quantification of low abundant VOCs, particularly alcohols and aldehydes [24]. The subject influence is also very pronounced because EB is highly dependent of the metabolism and therefore of the clinical characteristics of the subject, as age, gender, weight, diet, smoking habits, medication use, lifestyle and physical condition and existence of different diseases (liver impairment, diabetes, etc.) ([25,26]). Concerning the analytical aspects, there are again many bottlenecks in EB analysis: (a) lack of standardization of the experimental procedures, which would avoid broad variations in the results and (b) poor storage solutions or the deficient reliability of the available prototypes for EB real-time analysis. Nevertheless, breath analysis is having a large potential to offer an inexpensive, rapid and non-invasive diagnostic tool for several diseases [27-31]. Therefore, there is nowadays a consensual awareness throughout the scientific community that there are changes in the EB volatile composition that will allow us to obtain relevant information for diagnosis of several diseases, including CVD, NDD, OD, respiratory infections and diabetes. EB volatile composition has the potential to assess not only disease 
diagnosis, but also its severity, progression and response to treatment, although many improvements have to be done at the methodological level to achieve this goal.

\subsection{EB Analysis Experimental Layout}

EB analysis is technically challenging and could involve several experimental steps, depending on the methodology used. It is, therefore, prone to several experimental errors that will affect the quality of the results obtained if proper care is not taken. Moreover standard protocols/recommendations are not yet available albeit, many discussions about possible procedures in breath analysis. Nevertheless, as can be seen in Figure 1, EB analysis involves mainly three sequential steps: (a) Sampling and pre-concentration; (b) Analysis, processing of the data obtained and (c) Result output. Depending on the methodology selected, sampling and pre-concentration can be bypassed when EB is analysed in an online and realtime fashion. The statistical data processing that follows the sampling step can be particularly cumbersome due to data complexity in relation to sample size however. There is a full range of tools available to handle data complexity. However, there seems no consensus on selection and usage of tools to achieve discovery of volatile biomarkers that work with acceptable sensitivity and specificity for clinical applications.

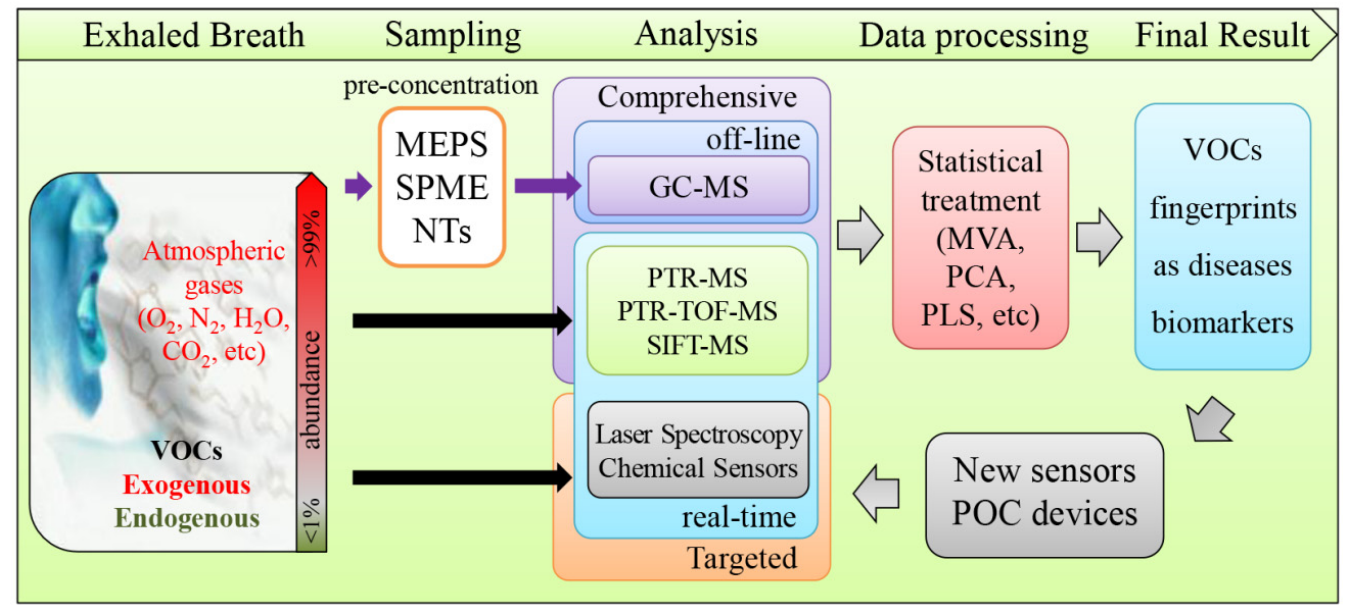

Figure 1. Generic layout for exhaled breath (EB) analysis. Abbreviations used: GC - gas chromatography, MEPS - microextraction by packed sorbent, POC-point of care, PTR-MS - proton transfer reaction with mass spectrometry, PTR-TOF-MS - proton transfer reaction with time-of-flight mass spectrometry, SIFT-MS-Selected ion flow tube mass spectrometry, NTDs - Needle Trap Devices, MVA - multivariated analysis, PCA—Principal Component Analysis, PLS—Partial least-square, VOCs—volatile organic compounds

\subsubsection{EB Sampling}

EB sampling is one of the most important steps in breath analysis and there are a number of parameters that researchers should pay attention, in order to avoid wrongful assumptions about the origin of the compounds identified. These parameters include the type and the number of breath collections, the portion of breath used, the EB storage and the interference of environmental VOCs from the collection room (reviewed in $[24,32,33]$ ). Breath collection can be achieved through a single breath or 
multiple breaths; both show associated advantages, which should be taken into account before choosing one of the two. For screening of potential compounds associated with a given disease and determination of a specific set of biomarkers, multiple breath analysis is required in order to achieve the best results, since it is more reproducible in terms of composition of the sample (reviewed in [24]). However, a single breath tends to be less time consuming and thus more acceptable for patients. EB can also be sampled in its full composition (total breath sample or mixed expiratory air) or, alternatively, only the alveolar air may be sampled. The first choice is more prone to contaminations, since the sampling control is very deficient. The patient just breathes for the sample collection device and therefore the risk of contamination with exogenous compounds from the oral cavity and dilutions in dead space are higher and may compromise the analysis (reviewed in [24]). These problems are reflected in the variation of the number of compounds and their concentration, jeopardizing the analytical reproducibility. In contrast, the alveolar air is richer in volatile blood-borne compounds [34]. Therefore the use of an alveolar air sampling approach, which can easily be achieved using a simple Capnograph to monitor the expiratory $\mathrm{CO}_{2}$ (Figure 2), is more accurate, assuring a more reliable sampling and consistent sample quality for within- and between-subject comparisons [34,35]. It would, therefore, be highly desirable that standardized procedures could be adopted for generic EB analysis as it was done for measurement of exhaled lower respiratory nitric oxide (NO) and nasal NO.

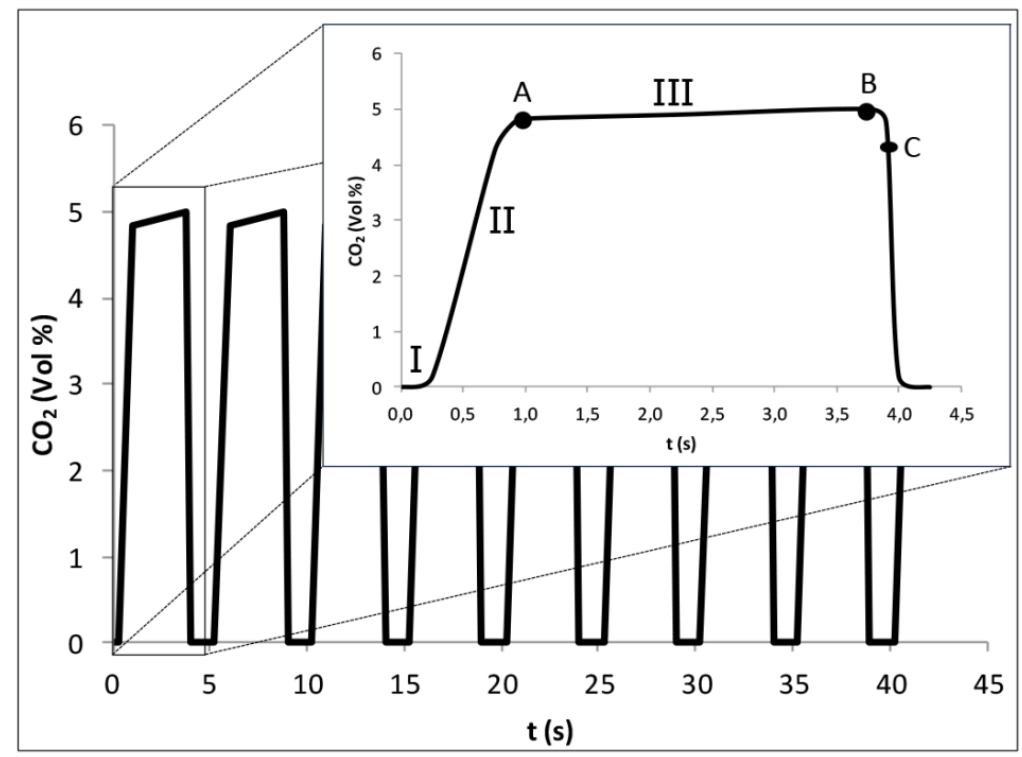

Figure 2. Exhaled CO2 monitoring by normal Capnograph: (A) —initial of alveolar sampling; (B) - final of alveolar sampling; (C) - final of exhalation. Differentiation phases of breathing: (I)-inspiratory phase; (II)-mixing phase; (III)-alveolar phase (adapted from [34,35]).

EB sampling can be performed directly or indirectly according to the type of analysis to be performed; we will see in more detail in the next section. In the off-line approach, EB has to be stored and concentrated before it is analysed. This procedure allows enrichment of the sample in the target analytes before its analysis [32]. EB storage can be made in the following ways [24,36]. The first approaches used Tedlar $^{\circledR}$ bags and canisters. The sampling bags are made from chemically inert materials as polyvinyl fluoride (PVF), perfluoroalkoxy polymer (PFA), polytetrafluoroethylene (PTFE) or 
polyvinylidene chloride (PVDC) [37]. These bags are impermeable to gas diffusion if covered with an aluminium foil [38] and their utilization is easy as they just need to be connected to a sample collection tube for EB collection. Tedlar ${ }^{\circledR}$ bags are reusable provided they are extensively purged with nitrogen flows to avoid problems of contamination and background VOCs [27,32,36,37,39], such as some phenols and $\mathrm{N}, \mathrm{N}$-dimethylacetamide. These compounds can be released in relatively higher concentrations, thus contaminating the samples [40]. Despite these advantages Tedlar ${ }^{\circledR}$ bags are vulnerable to punctures and some breath constituents, such as hexanal and isoprene cannot be stored for more than a few hours, thus limiting the utility of Tedlar $^{\circledR}$ bags for typical clinical studies [41,42]. It is possible that Tedlar $^{\circledR}$ bags can potentially give rise to biased results in which cases use of Tenax tubes is more appropriate [43,44]. Canisters are stainless steel recipients with an electropolished inner surface. This is necessary to reduce the adsorption of certain compounds and prevent their loss. Canisters are robust with long shelflife [32,37], but their utilization is not suitable for sample collection (costs, space, storage, etc.) [37]. Another way to collect breath samples is using gas-tight syringes. A $50 \mathrm{~mL}$ syringe, for instance, is connected to a mouthpiece and patients breathe normally. Typically $10-20 \mathrm{~mL}$ of EB is drawn into the syringe and transferred to pre-evacuated glass vials $(20 \mathrm{~mL})$, where EB is stored before analysed. This procedure can be used both for mixed air as well as alveolar air $[35,45]$. The EB is saturated with water vapour and therefore can be condensed with cooling [46]. This exhaled breath condensate (EBC) is another form of sampling storage, but it is out of the scope of this review and extensive descriptions about it can be found elsewhere [47-51].

\subsubsection{Pre-Concentration}

As already mentioned, the volatile composition of interest in EB represents less than $1 \%$ of its composition and can range from $\mu \mathrm{mol} \mathrm{L}-1$ to fmol L$~^{-1}[25,35]$. Therefore, small interfering compounds could affect the analytical results. To minimize this effect, an intermediate step between sampling and analysis is sometimes necessary and advantageous to increase the concentration level of the target analytes over the possible interfering compounds. There are several enrichment techniques available, such as cryogenic trapping, usually used with the canister breath sampling, and adsorption in different thermal desorption tubes (TD-tubes), sorbent traps and coated fibres. The adsorption option requires a thermodesorption step, being usually followed by gas chromatography combined with mass spectrometry (GC/MS). A wide range of TD-tubes, also known as sorbent tubes, are available with different strength abilities to retain VOCs, working temperatures and hydrophobicity (reviewed in [52,53]). Therefore, applications of TD-tubes are also very broad and include, among others, environmental control [54], natural products characterisation [55], and breath research for disease diagnosis (as reported in [43,56-58]) (Table 1). Among the TD sorbents, Tenax tubes are quite popular for breath analysis as they allow a good performance in terms of pre-concentration and transport of breath samples before processing [43,56-59]). The multibed versions of TD-tubes, in which different sorbents with increasing strength are packed sequentially, are particularly suitable for breath analysis given the broad range in volatility of the VOCs present in EB samples [52]. Among the EB sample concentration methods, Solid-Phase Microextraction (SPME) is the most popular adsorption methodology [32,35,45,60,61]. This technique, particularly its headspace variant (HS-SPME), in which the extraction of the analytes belonging to solid or liquid sample is taken from the headspace, has gained tremendous importance with regard to the EB sampling. Based on 
the equilibrium partitioning of the analyte in the sample matrix and stationary phase, the HS-SPME extraction/concentration is more effective from the moment the analyte reaches the equilibrium concentration in the fibre, and its concentration in the extraction fibre remains constant [62-64]. The HS-SPME device is composed of a coated, silica fibre, with a thin layer $(5-100 \mathrm{~nm})$ of a suitable polymeric adsorbent. Many types of adsorbent are available in the market, for example, PDMS, CAR, DVB, combinations of these, and others. The selection of the fibre type and its thickness is usually done according to the polarity and molecular weight of the VOCs. In EB analysis, the CAR/PDMS stationary phases have shown great performance, however, the search for improved materials is still ongoing [62-65]. Additional factors affecting SPME performance, such as temperature and time of extraction, sample $\mathrm{pH}$ and ionic strength, are very important and must be optimized to obtain the best results. A more detailed overview about this experimental optimization can be found elsewhere (reviewed in [4,66-68]). An emerging and promising alternative that combines the EB sampling and pre-concentration steps in a single device is the Needle Trap Device (NTD) [69-72]. The NTD is a trap device composed of a needle containing a sorbent material packed inside. The sorbent constitution is variable and includes Carboxen (CAR), Divinylbenzene (DVB), Polydimethylsiloxane (PDMS), mixtures of these, and other sorbents (similar to the composition of SPME and TD-tubes). In the NTD, the sample can be actively drawn in and out by diffusion, gas-tight syringe or automated devices, such as vacuum pumps. The sensitivity that can be achieved using NTDs is comparable to SPME. Unlike SPME, NTD is an exhaustive methodology, allowing an increase in the concentration of several compounds by using more sample volume. The working principles behind NTDs are quite similar to the TD-tubes. However, their use is technically easier and straightforward since the steps, sampling, pre-concentration and sample injection (that can be made in a regular GC using thermal desorption and a lower internal diameter liner) occur sequentially and using a single device. Moreover, sample storage, prior to analysis, is also possible and has been shown to deliver reproducible results for several days or even weeks of storage, depending on the target analytes [41]. In summary, given the particularities and requirements of breath analysis, NTD seems to present substantial advantages over TD-tubes and SPME and its popularity will certainly grow exponentially in the next years. Similar to TDtubes, the NTD multibed configurations are the most appropriate to retain the wide volatile composition of EB [41].

\subsection{EB Analysis}

Since Pauling et al. reported for the first time the volatile composition of EB, in 1971 [18], several methodological improvements have been introduced in breath analysis. Therefore, nowadays, EB analysis is no longer restricted to the off-line laboratory approaches, often gas-chromatography (GC) hyphenated methodologies, as GC coupled with mass spectrometry (GC-MS), GC coupled with flame ionization detection (GC-FID), GC coupled with ion mobility spectrometry (GC-IMS), and several real-time $\mathrm{EB}$ analysis options are available. Real-time $\mathrm{EB}$ analysis includes proton transfer reaction mass spectrometry (PTR) and its variations (PTR-MS and proton transfer reaction-time-of flight-mass spectrometry (PTR-TOF-MS)), IMS and IMS coupled with multi-capillary columns (MCC/IMS), the fast flow and flow-drift tube techniques called selected ion flow tube mass spectrometry (SIFT-MS) (reviewed in $[30,73,74]$ ). More recently, a plethora of laser spectroscopy approaches and sensors, commonly known as electronic noses (e-noses) (reviewed in [75,76]), have been developed and 
applied to EB analysis with promising results (in Table 1 are indicated some examples). These real-time options reduce several unnecessary experimental steps related with sampling, storage and pre-concentration of EB. Moreover, most of them are able to deliver high-sensitivity and high-selectivity in the same range of MS methodologies while operating near real time using potentially inexpensive point of care (POC) devices [75]. One of the most notable advantages of these POC devices is in their utilization in large epidemiological studies. These sensor approaches, however, are confined to the characterisation of a very limited number of target VOCs and their ability to simultaneously identify the broad chemical variation of EB VOCs has to be improved. Alternatively, many e-nose approaches rely on pattern recognition and do qualitative characterisation of different classes of volatiles as compared with the devices that give absolute quantification of volatiles. Either quantitative or qualitative characterisation, the target VOCs have to be identified by comprehensive methodologies, usually involving MS detection. Unfortunately, these comprehensive methodologies are very expensive, requiring highly specialized and skilled operators. The search for a reliable technology for breath analysis is still therefore in progress as there is no single methodology available yet to deliver, for instance, the GC-MS resolution in a real-time approach using an affordable point of care (POC) device.

\subsubsection{Off-line Analysis: Gas-Chromatography (GC)}

GC was the analytical method chosen for the initial studies in breath analysis [18,77-80] and even today it is one of the preferred methods when coupled to MS. In fact, almost all of the EB VOCs reported so far have been identified and quantified using MS-based methods, most often GC-MS [75]. GC-MS is possibly the most comprehensive and sensitive approach to characterize EB volatile composition, allowing the selective analysis of one or simultaneous analysis of many compounds that may be in the range from ppb to ppt. The GC-MS involves separation of volatilized samples in chromatographic column based on different parameters, such as polarity of the GC column or the boiling point of the sample components (reviewed in [81]). GC-MS system ionizes the target ions, separate them by mass to-charge (m/z) ratios and uses the resolved fragmentation patterns to quantify the amount of each specific VOC in the sample [81]. There are, however, other detection systems that have been coupled to GC for breath analysis, namely FID and IMS. In the first case, VOCs are burned in the FID, producing ions and electrons that can conduct the electric potential and this information is used for detection and eventually quantification. GC-FID generally exhibits a fairly high sensitivity, large linear response range, and low noise. However, the FID detector is mass sensitive and its response is not altered significantly by changes in mobile-phase flow rate (reviewed in [14]). In turn, in the IMS, ions are separated according to their mobility as they travel through a purified gas, in an electric field at the atmospheric pressure. The IMS detector is also selective, allowing the quantification of VOCs in the EB (reviewed in [14,74]). Regardless

of the detection method used in a GC analysis, this approach presents, however, some drawbacks, the most notable being the requirement for sample pre-treatment (sampling and pre-concentration). Therefore, a GC analysis is only suitable for indirect sampling and not for real-time analysis, being a time-consuming process (a typical GC-MS analysis can take up to an hour). Thus, analytes loss and degradation, particularly of those of reactive or thermally labile metabolites, and possible contaminations, are the important concerns inherent to the sample pre-treatment that need to be carefully addressed to improve the quality of the data obtained in a GC analysis $[24,33,36,45,75]$. 
Table 1. Characterisation of selected exhaled breath (EB) volatile organic compounds (VOCs) reported in the literature.

\begin{tabular}{|c|c|c|c|c|c|}
\hline Target VOCs (Putative Biomarkers) (LODs) & Methodology & $\begin{array}{l}\text { Sample } \\
\text { (Patients/ } \\
\text { Controls) }\end{array}$ & $\begin{array}{c}\text { Sensitivity/ } \\
\text { Specificity (\%) }\end{array}$ & $\begin{array}{l}\text { Statistical Approach } \\
\text { (Pre-Processing Method; } \\
\text { Classification Method; } \\
\text { Performance Measures) }\end{array}$ & Reference \\
\hline \multicolumn{6}{|c|}{ Oncologic Diseases } \\
\hline \multicolumn{6}{|c|}{ Lung cancer (LC) } \\
\hline 1-octene & $\begin{array}{c}\text { SPME/GC-MS } \\
\text { Chemical nanoarrays }\end{array}$ & $72 / 10$ & $\begin{array}{l}\text { DFA model: } \\
86.0 / 96.0 \\
\text { Cross-validation: } \\
86.0 / 88.0\end{array}$ & $\begin{array}{c}\text { LDA; } \underline{\text { Wilcoxon// }} \\
\text { Kruskal-Wallis ANOVA }\end{array}$ & {$[82]$} \\
\hline $\begin{array}{l}\text { isoprene (81.5 ppb), acetone (458.7 ppb), } \\
\text { methanol (118.5 ppb) }\end{array}$ & PTR-MS/GC-MS & $285 / 472$ & $\begin{array}{l}4 \text { compounds: } \\
52.0 / 100 ; \\
15 \text { (or } 21) \\
\text { compounds: } \\
71.0(80.0) / 100 \\
\end{array}$ & $\underline{\text { Kruskal-Wallis ANOVA }}$ & {$[30]$} \\
\hline $\begin{array}{l}\text { isoprene }(6041 \mathrm{pM}) \text {, pentane }(647.5 \mathrm{pM}) \text {, } \\
\text { heptane }(13.5 \mathrm{pM}) \text {, octane }(61.0 \mathrm{pM}) \\
\text { styrene }(17.9 \mathrm{pM}) \text {, among } 13 \mathrm{VOCs}\end{array}$ & SPME/GC-MS & $36 / 50$ & $72.2 / 93.6$ & $\begin{array}{l}\text { Kolmogorov-Smirnov; } \underline{\text { ANOVA, Games }} \\
\text { Howell post-hoctest; Kruskal-Wallis } \\
\text { ANOVA, Dunn's Post Hoc test; } \\
\text { Student } t \text {-test; } p \text {-value; PRISM }\end{array}$ & {$[83]$} \\
\hline $\begin{array}{l}\text { 2-butanone (1.78-8.38 nM), } \\
\text { 2-hydroxyacetaldehyde }(0.13-0.77 \mathrm{nM}) \text {, } \\
\text { 3-hydroxy-2-butanone }(0.23-1.13 \mathrm{nM}) \text {, } \\
\text { 4-hydroxyhexenal }(0.005-0.05 \mathrm{nM})\end{array}$ & FT-ICR-MS & $97 / 88$ & $89.8 / 81.3$ & $\underline{\text { Wilcoxon (Minitab) }}$ & {$[39]$} \\
\hline formaldehyde (7 ppb) & PTR-MS & $17 / 170$ & $54.0 / 99.0$ & $\begin{array}{l}\text { FQDM; } p \text {-values from Wilcoxon; } \\
\text { ROC; MATLAB (classify.m) }\end{array}$ & {$[84]$} \\
\hline $\begin{array}{l}\text { pentanal }(0.001 \mathrm{nM}) \\
\text { hexanal }(0.010 \mathrm{nM}) \\
\text { octanal }(0.009 \mathrm{nM}) \\
\text { nonanal }(0.028 \mathrm{nM})\end{array}$ & OFD-SPME/GC-MS & $12 / 12,12$ & $\begin{array}{l}\text { C5: } 75.0 / 95.5 \\
\text { C6: } 8.3 / 91.7 \\
\text { C8: } 58.3 / 91.7 \\
\text { C9: } 33.3 / 95.8\end{array}$ & $\underline{\text { Kruskal-Wallis ANOVA }}$ & {$[85]$} \\
\hline
\end{tabular}


Table 1. Cont.

\begin{tabular}{|c|c|c|c|c|c|}
\hline Target VOCs (Putative Biomarkers) (LODs) & Methodology & $\begin{array}{l}\text { Sample } \\
\text { (Patients/ } \\
\text { Controls) }\end{array}$ & $\begin{array}{l}\text { Sensitivity/ } \\
\text { Specificity } \\
\text { (\%) }\end{array}$ & $\begin{array}{l}\text { Statistical Approach } \\
\text { (Pre-Processing Method; } \\
\text { Classification Method; } \\
\text { Performance Measures) }\end{array}$ & Reference \\
\hline ethane & GC-FID & $26 / 14$ & - & $\begin{array}{c}\text { ANOVA with Bonferroni's correction } \\
\text { for multiple comparisons }\end{array}$ & {$[86]$} \\
\hline $\begin{array}{c}\text { isoprene }(0.095 \mathrm{nM}) \text {, acetone }(0.985 \mathrm{nM}) \text {, } \\
\text { 2-butanone }(0.158 \mathrm{nM}) \text {, ethanol }(5.098 \mathrm{nM}) \text {, } \\
\text { acetaldehyde }(1.280 \mathrm{nM}) \text {, pentanal }(0.436 \mathrm{nM}) \text {, } \\
\text { dimethyl sulphide }(0.270 \mathrm{nM}) \text {, pentane }(0.431 \mathrm{nM})\end{array}$ & SPME/GC-MS & $31 / 31,31$ & - & $\begin{array}{c}\text { PCA, Mann-Whitney Rank; } \\
\text { Kruskal-Wallis ANOVA; post hoc } \\
\text { Student-Newman-Keuls; Dunn's Method }\end{array}$ & [87] \\
\hline $\begin{array}{l}\text { hexane, methylpentane, o-toluidine, } \\
\text { aniline, alcohols, ketones }\end{array}$ & e-nose, GC-MS & $42 / 18$ & Good & PLS-DA & {$[88]$} \\
\hline $\begin{array}{c}\text { styrene, decane, isoprene, benzene, undecane, } \\
\text { 1-hexene, hexanal, propyl benzene, } \\
\text { 1,2,4-trimethyl benzene, heptanal, methyl cyclopentane }\end{array}$ & $\begin{array}{l}\text { SPME, virtual SAW gas } \\
\text { sensor }\end{array}$ & $20,7 / 15$ & Good & $A N N$ & [89] \\
\hline $\begin{array}{l}\text { isobutene, methanol, ethanol, acetone, pentane, } \\
\text { isoprene, isopropanol, dimethylsulfide, } \\
\text { carbon disulphide, benzene, toluene }\end{array}$ & e-nose, GC-MS & $14 / 45 ; 14 / 62$ & $71.4 / 91.9$ & PCA, CDA, SVM & {$[90]$} \\
\hline VOCs pattern recognition & colorimetric sensors & $\begin{array}{l}49,18,15 \\
20,20 / 21\end{array}$ & $\begin{array}{l}\text { Model validation: } \\
73.3 / 72.4 \\
21 \text { patients: } \\
100 / 60.0\end{array}$ & Random forest classifier & [91] \\
\hline VOCs pattern recognition & e-nose & $10,10 / 10$ & - & 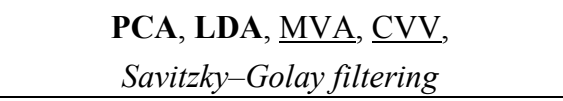 & {$[92]$} \\
\hline Set of 42 VOCs & $\begin{array}{l}\text { gold nanoparticle sensors, } \\
\text { SPME/GC-MS }\end{array}$ & $40 / 56$ & - & PCA & [93] \\
\hline VOCs pattern recognition & colorimetric sensors & $92 / 137$ & $\begin{array}{l}\text { High, several } \\
\text { groups defined }\end{array}$ & Logistic prediction model & [94] \\
\hline
\end{tabular}


Table 1. Cont.

\begin{tabular}{|c|c|c|c|c|c|}
\hline Target VOCs (Putative Biomarkers) (LODs) & Methodology & $\begin{array}{l}\text { Sample } \\
\text { (Patients/ } \\
\text { Controls) }\end{array}$ & $\begin{array}{l}\text { Sensitivity/ } \\
\text { Specificity } \\
\text { (\%) }\end{array}$ & $\begin{array}{l}\text { Statistical Approach } \\
\text { (Pre-Processing Method; } \\
\text { Classification Method; } \\
\text { Performance Measures) }\end{array}$ & Reference \\
\hline 2-hexanone, 3-heptanone; 2,2,4-Trimethyl-hexane & SPME/GC-MS, sensors & $12,4,-1$ & $100 / 80$ & LDA & [95] \\
\hline VOCs profile & $\begin{array}{c}\text { PTR-MS, } \\
\text { SPME-GC-MS }\end{array}$ & $\begin{array}{c}220 / 441 \\
65 / 31 \\
\end{array}$ & variable & - & {$[30]$} \\
\hline \multicolumn{6}{|c|}{ Mesothelioma } \\
\hline VOCs pattern recognition & e-nose & $38 / 42$ & $95 / 88$ & $\begin{array}{c}\text { PCA, LDA; } \\
\text { Inbuilt Savitzky-Golay filtering }\end{array}$ & [96] \\
\hline cyclopentane $(0.40 \mathrm{ng} / \mathrm{L})$, cyclohexane $(4.67 \mathrm{ng} / \mathrm{L})$ & TD-GC-MS & $13+13 / 13$ & $92.3 / 82.7$ & PCA, DFA and CP-ANN; ANOVA & {$[97]$} \\
\hline VOCs pattern recognition & e-nose & $13,13 / 13$ & $92.3 / 82.7$ & PCA, DA; MVA & {$[98]$} \\
\hline \multicolumn{6}{|c|}{ Breast Cancer (BC) } \\
\hline $\begin{array}{l}\text { nonane; 5-methyl-tridecane; 3-methyl-undecane; } \\
\text { 6-methyl-pentadecane; 2-methyl-propane; } \\
\text { 3-methyl-nonadecane; 4-methyl-dodecane; } \\
\text { 2-methyl-octane }\end{array}$ & TD-GC-MS & $51 / 102$ & $94.1 / 73.8$ & $\begin{array}{c}\text { positive predictive value and } \\
\text { negative predictive value }\end{array}$ & {$[99]$} \\
\hline $\begin{array}{l}\text { undecane, dodecane, tridecane, } \\
\text { tetradecane, pentadecane, D-limonene }\end{array}$ & TD-GC-MS & $54 / 204$ & $78.5 / 88.3$ & $\begin{array}{c}\underline{\mathrm{ROC}}, \mathrm{MCCV}, \underline{\mathrm{MVA} \text { algorithm }} \\
\underline{\text { employing WDA }}\end{array}$ & {$[100]$} \\
\hline $\begin{array}{c}\text { 3,3-Dimethyl-pentane, } \\
\text { 5-(2-Methylpropyl)-nonane, 2,3,4-Trimethyl-decane, } \\
\text { 2-Amino-5-isopropyl-8-methyl-1-azulenecarbonitrile, } \\
\text { 1-Iodo-nonane }\end{array}$ & GC-MS & $22 / 22$ & - & PCA and cluster analysis & [101] \\
\hline $\begin{array}{c}\text { hexanal (3.75 ppbV), heptanal (3.22 ppbV), } \\
\text { octanal (3.39 ppbV), nonanal (2.49 ppbV) }\end{array}$ & GC-MS & $22,17 / 24$ & $72.7 / 91.7$ & $\begin{array}{l}\text { Fisher DA; leave-one-out (LOO) DA; } \\
\text { Kruskal-Wallis ANOVA, ROC, AUC }\end{array}$ & [102] \\
\hline $\begin{array}{c}\text { VOCs profile (A: BC on biopsy/normal screening } \\
\text { mammograms (scr mam), B: normal/abnormal scr mam, } \\
\text { C: BC/no BC on biopsy) }\end{array}$ & $\begin{array}{c}\text { POC device } \\
\text { (TD-GC-SAW) }\end{array}$ & $37+35 / 172$ & $\begin{array}{c}\mathbf{A}(81.8 / 70) \\
\mathbf{B}(86.5,66.7) \\
\mathbf{C}(75.8,74.0)\end{array}$ & $\begin{array}{l}\text { C-statistic ([AUC] of [ROC]), MCCV } \\
\frac{\text { MVA algorithm cross validated }}{\text { with a LOO method }} \\
\end{array}$ & {$[103]$} \\
\hline VOCs pattern recognition & e-nose & $16,13 / 7$ & $94 / 80$ & PCA, SVM, cross validation & [104] \\
\hline
\end{tabular}


Table 1. Cont.

\begin{tabular}{|c|c|c|c|c|c|}
\hline Target VOCs (Putative Biomarkers) (LODs) & Methodology & $\begin{array}{l}\text { Sample } \\
\text { (Patients/ } \\
\text { Controls) }\end{array}$ & $\begin{array}{l}\text { Sensitivity/ } \\
\text { Specificity } \\
\text { (\%) }\end{array}$ & $\begin{array}{c}\text { Statistical Approach } \\
\text { (Pre-Processing Method; } \\
\text { Classification Method; } \\
\text { Performance Measures) }\end{array}$ & Reference \\
\hline \multicolumn{6}{|c|}{ Colorectal cancer (CRC) } \\
\hline $\begin{array}{c}\text { decanal; 1,3-dimethylbenzene; 1,2-pentadiene } \\
\text { Cyclohexane; Methyl cyclohexane; 4-methyloctane }\end{array}$ & GC-MS & $37 / 41$ & $86 / 83$ & PNN validated by the LOO method & {$[27]$} \\
\hline 10 discriminant VOCs & SPME/GC-MS & $20 / 20$ & - & PCA, PLS-DA & {$[45]$} \\
\hline 4 discriminant VOCs & GC-MS & $26 / 22$ & - & PCA and cluster analysis & {$[101]$} \\
\hline \multicolumn{6}{|c|}{ Gastric cancer } \\
\hline 6 discriminant VOCs & sensors, GC-MS & $37,32,-61$ & $89 / 90$ & $\begin{array}{c}\text { LDA; } \underline{\text { Wilcoxon/ }} \\
\text { Kruskal-Wallis ANOVA }\end{array}$ & {$[105]$} \\
\hline \multicolumn{6}{|c|}{ Head-and-neck cancer } \\
\hline 8 discriminant VOCs & e-nose, GC-MS & $22,25 / 40$ & $100 / 100$ & PCA with $\underline{\text { ANOVA and Student }}$ & {$[106]$} \\
\hline VOCs pattern recognition & e-nose & $36 / 23$ & $90 / 80$ & $\underline{\text { Logistic regression, }} \underline{\mathrm{ROC}}$ & {$[107]$} \\
\hline \multicolumn{6}{|c|}{ Liver cancer } \\
\hline $\begin{array}{l}\text { 2,3-dihydro-benzofuran, } \\
\text { methane-sulfonyl chloride; acetic acid; ethanol }\end{array}$ & sensor, GC-MS & & $95.8 / 100$ & $\begin{array}{l}\text { LDA; Shapiro-Wilk, Wilcoxon/ } \\
\underline{\text { Kruskal-Wallis ANOVA }}\end{array}$ & {$[108]$} \\
\hline hexanal; 1-octen-3-ol; octane & SPME/GC-MS & $18 / 19$ & $100 / 100$ & $\underline{\mathrm{RSD}} ; \chi^{2}$ & {$[109]$} \\
\hline $\begin{array}{c}\text { 3-Hydroxy-2-butanone, styrene, and decane } \\
\text { (set A: HCC patients/normal controls; } \\
\text { B: cross-validation) }\end{array}$ & GC-MS & $30 / 27+36$ & $\begin{array}{l}\text { A: } 86.7 / 91.7 \\
\text { B. } 83.3 / 91.7\end{array}$ & $\underline{\text { ROC and DA using the defined markers }}$ & {$[110]$} \\
\hline \multicolumn{6}{|c|}{ Pulmonary Diseases } \\
\hline \multicolumn{6}{|c|}{ Airways inflammation } \\
\hline VOCs pattern recognition & e-nose & $110 / 108$ & $72.2 / 75.1$ & $\begin{array}{c}\text { k-NN voting rule to classify features } \\
\text { extracted by PCA }\end{array}$ & [111] \\
\hline
\end{tabular}


Table 1. Cont.

\begin{tabular}{|c|c|c|c|c|c|}
\hline Target VOCs (Putative Biomarkers) (LODs) & Methodology & $\begin{array}{l}\text { Sample } \\
\text { (Patients/ } \\
\text { Controls) }\end{array}$ & $\begin{array}{l}\text { Sensitivity/ } \\
\text { Specificity } \\
\text { (\%) }\end{array}$ & $\begin{array}{c}\text { Statistical Approach } \\
\text { (Pre-Processing Method; } \\
\text { Classification Method; } \\
\text { Performance Measures) }\end{array}$ & Reference \\
\hline \multicolumn{6}{|c|}{ Asthma } \\
\hline $\begin{array}{l}\text { Several discriminant VOCs, } \\
\text { including acetone and many alkanes }\end{array}$ & e-nose, GC-MS & $20 / 20$ & - & $\begin{array}{l}\text { PCA; cross-validation value, } \\
\text { LDA on principal component reduction, } \\
\underline{\text { M-distance }}\end{array}$ & [112] \\
\hline $\begin{array}{c}\text { decane; dodecane; tetradecane; 2-methyl-1,3-butadie } \\
\text { 2,2-dimethylhexane; 2,4-dimethyloctane, } \\
\text { 2,3,6-trimethyldecane }\end{array}$ & GC-MS & $35 / 15$ & - & PLS-DA; $\underline{\text { Single factor ANOVA }}$ & {$[113]$} \\
\hline $\begin{array}{c}\text { nonane; 2,2,4,6,6-pentamethylheptane; decane; } \\
\text { 3,6-dimethyldecane; dodecane; tetradecane }\end{array}$ & GC-MS & $32 / 27$ & $96 / 95$ & $\begin{array}{c}\text { PLS-DA, Monte Carlo cross-validation } \\
(\mathrm{MCCV}) \text { statistics }\end{array}$ & {$[114]$} \\
\hline Several discriminant VOCs & GC-MS & $63 / 57$ & $89 / 95$ & Stepwise DA; 20-fold CVV DA & {$[115]$} \\
\hline VOCs pattern recognition & e-nose/GC-MS & $27 / 24$ & $\begin{array}{l}\text { High, several } \\
\text { groups defined }\end{array}$ & PCA, $A N N$ & {$[116]$} \\
\hline 17 discriminant VOCs & GC-TOF-MS & 252 & high & $\begin{array}{c}\text { Random Forests (RF) and } \\
\text { dissimilarity PLS-DA } \\
\end{array}$ & {$[117]$} \\
\hline \multicolumn{6}{|c|}{ Acute Respiratory Distress Syndrome (ARDS) } \\
\hline octane, acetaldehyde and 3-methylheptane & GC-MS & $23 / 53$ & 90 & $\begin{array}{l}\text { Kruskal-Wallis ANOVA (continuous } \\
\text { variables), } \chi^{2} \text { (categorical variables) }\end{array}$ & [118] \\
\hline acetone, isoprene, $\mathrm{n}$-Pentane & GC-FID/GC-MS & $19 / 18$ & - & $\begin{array}{c}\frac{\text { Mann-Whitney U-Wilcoxon rank sum test }}{\text { (unpaired samples), Wilcoxon }} \\
\text { matched-pairs signed-ranks test } \\
\text { (paired samples) }\end{array}$ & [119] \\
\hline \multicolumn{6}{|c|}{ Pulmonary embolism } \\
\hline VOCs pattern recognition & e-nose & $40 / 20$ & $85 / 65$ & LDA, PCA, $\underline{\text { ROC }}$ & {$[120]$} \\
\hline
\end{tabular}


Table 1. Cont.

\begin{tabular}{|c|c|c|c|c|c|}
\hline Target VOCs (Putative Biomarkers) (LODs) & Methodology & $\begin{array}{l}\text { Sample } \\
\text { (Patients/ } \\
\text { Controls) }\end{array}$ & $\begin{array}{l}\text { Sensitivity/ } \\
\text { Specificity } \\
\text { (\%) }\end{array}$ & $\begin{array}{c}\text { Statistical Approach } \\
\text { (Pre-Processing Method; } \\
\text { Classification Method; } \\
\text { Performance Measures) }\end{array}$ & Reference \\
\hline \multicolumn{6}{|c|}{ Pulmonary Tuberculosis } \\
\hline 6 discriminant VOCs & $\mathrm{GC} / \mathrm{MS}$ & $42 / 59$ & $95.7 / 78.9$ & $\begin{array}{c}\text { Fuzzy logic, Pattern recognition analysis; } \\
\text { PLS, HCA, PCA, k-NN; } \\
\text { PC regression, ROC, SIMCA }\end{array}$ & {$[121]$} \\
\hline VOCs pattern recognition & $\begin{array}{c}\text { POC device } \\
\text { (TD-GC-SAW) }\end{array}$ & $130 / 121$ & $71.2 / 72$ & $\begin{array}{c}\text { MCCV, multivariate predictive } \\
\text { algorithm; } \underline{\mathrm{ROC}}\end{array}$ & {$[122]$} \\
\hline $\begin{array}{c}\text { Alkanes and derivatives, } \\
\text { cyclohexane and benzene derivatives }\end{array}$ & $\mathrm{GC} / \mathrm{MS}$ & 226 & variable & $\mathrm{MCCV}$ & {$[123]$} \\
\hline \multicolumn{6}{|c|}{ Chronic Obstructive Pulmonary Disease (COPD)/Emphysema } \\
\hline $\begin{array}{c}\text { Ethane (No steroid treatment }-2.77 \pm 0.25 \mathrm{ppb} \\
\text { Steroid-treated }-0.48 \pm 0.05 \mathrm{ppb})\end{array}$ & GC-FID & $22 / 14$ & - & $\begin{array}{c}p \text {-value; } \text { ANOVA-two-way } \\
\text { variance analysis }\end{array}$ & {$[124]$} \\
\hline $\begin{array}{c}\text { MDA }(57.2 \mathrm{nM}), \text { hexanal }(63.5 \mathrm{nM}) \\
\text { heptanal }(26.6 \mathrm{nM})\end{array}$ & LC-MS/MS & $20 / 12,20$ & - & p-value; Wilcoxon, Bland-Altman & {$[125]$} \\
\hline Mass-spectra & PTR-MS & - & $43 / 161$ & $\begin{array}{c}\text { bootstrapped stepwise forward } \\
\underline{\text { logistic regression }}\end{array}$ & {$[126]$} \\
\hline VOCs pattern recognition & eNose & $33 / 10$ & $100 / 100$ & LDA; Wilcoxon, $\underline{\text { k-fold cross-validation }}$ & {$[127]$} \\
\hline VOCs profile & MCC/IMS & $\begin{array}{l}\text { High, } \\
\text { variable with } \\
\text { statist. used }\end{array}$ & $30+54 / 35$ & $\begin{array}{c}\text { decision tree, naive Bayes, linear support } \\
\text { vector machine (SVM), ANN, } \\
\boldsymbol{R} \boldsymbol{F} \text { and radial SVM } \\
\end{array}$ & {$[128]$} \\
\hline
\end{tabular}


Table 1. Cont

\begin{tabular}{|c|c|c|c|c|c|}
\hline Target VOCs (Putative Biomarkers) (LODs) & Methodology & $\begin{array}{c}\text { Sample } \\
\text { (Patients/ } \\
\text { Controls) }\end{array}$ & $\begin{array}{c}\text { Sensitivity/ } \\
\text { Specificity } \\
\text { (\%) }\end{array}$ & $\begin{array}{c}\text { Statistical Approach } \\
\text { (Pre-Processing Method; } \\
\text { Classification Method; } \\
\text { Performance Measures) }\end{array}$ & Reference \\
\hline \multicolumn{6}{|c|}{ Cystic Fibrosis (CF) } \\
\hline pentane (0.36 ppb), dimethyl sulphide (3.9 ppb) & GC-MS & $20 / 20$ & - & Wilcoxon; linear regression & [129] \\
\hline $\begin{array}{l}\text { carbonyl sulphide }(110 \pm 60 \text { pptv }) \text {, dimethyl sulphide } \\
(4.780 \pm 1.350 \text { pptv), carbon disulphide }(26 \pm 38 \text { pptv })\end{array}$ & GC-MS & $20 / 23$ & - & $\begin{array}{l}\text { Student; } ; \underline{\text { F-score method; }} \\
\text { Pearson; Fisher's z-score }\end{array}$ & {$[130]$} \\
\hline $\begin{array}{c}\text { ethane (no steroid treatment }-1.99 \pm 0.20 \mathrm{ppb} \text {; steroid } \\
\text { treatment }-0.67 \pm 0.11 \mathrm{ppb})\end{array}$ & GC-FID & $23 / 14$ & - & $\underline{\text { ANOVA with Bonferroni's correction }}$ & {$[131]$} \\
\hline \multicolumn{6}{|c|}{ Other Diseases } \\
\hline \multicolumn{6}{|c|}{ Cardiovascular Diseases (CVDs) } \\
\hline \multicolumn{6}{|c|}{ Acute decompensated heart failure (ADHF) } \\
\hline acetone $(256-1974 \mathrm{ppb})$, pentane $(20-74 \mathrm{ppb})$ & SIFT-MS & $25 / 16$ & - & $\underline{\text { MVA }}$ & {$[28]$} \\
\hline acetone $(3.7 \mathrm{ppb})$ & GC-MS & $59,30 / 20$ & $83 / 100$ & $\underline{\text { Kruskal-Wallis ANOVA }}$ & [132] \\
\hline \multicolumn{6}{|c|}{ Cholesterol } \\
\hline Isoprene & GC/MS, SIFT-MS & & - & - & [29] \\
\hline \multicolumn{6}{|c|}{ Atherosclerosis } \\
\hline trimethyl amine & GC, SIFT-MS & & - & - & {$[29]$} \\
\hline \multicolumn{6}{|c|}{ Carbohydrate malabsorption/maldigestion } \\
\hline Ethanethiol, dimethylsulfide & PTR-MS & & - & - & {$[133]$} \\
\hline \multicolumn{6}{|c|}{ Liver dysfunctions } \\
\hline \multicolumn{6}{|c|}{ Liver Cirrhosis } \\
\hline $\begin{array}{l}\text { 2-butanone }(3.2 \pm 0.5 \mathrm{ppbv}) \text {, } \\
\text { methanol }(528 \pm 218 \mathrm{ppbv}) \\
\text { heptadienol }(2.5 \pm 1.4 \mathrm{ppbv}) \\
\text { monoterpenes }(6.7 \pm 5 \mathrm{ppbv})\end{array}$ & PTR-TOF-MS & $12 / 14$ & $83 / 86$ & p-value; DA; Wilcoxon, Pearson & {$[5]$} \\
\hline
\end{tabular}


Table 1. Cont.

\begin{tabular}{|c|c|c|c|c|c|}
\hline Target VOCs (Putative Biomarkers) (LODs) & Methodology & $\begin{array}{c}\text { Sample } \\
\text { (Patients/ } \\
\text { Controls) }\end{array}$ & $\begin{array}{l}\text { Sensitivity/ } \\
\text { Specificity } \\
\text { (\%) }\end{array}$ & $\begin{array}{c}\text { Statistical Approach } \\
\text { (Pre-Processing Method; } \\
\text { Classification Method; } \\
\text { Performance Measures) }\end{array}$ & Reference \\
\hline \multicolumn{6}{|c|}{ Non-Alcoholic Fatty Liver Disease (NAFLD) } \\
\hline $\begin{array}{l}\text { acetone }(71.7 \mathrm{ppb}) \text {, isoprene }(14.7 \mathrm{ppb}) \text {, } \\
\text { trimethylamine }(5 \mathrm{ppb}) \text {, acetaldehyde }(35.1 \mathrm{ppb}) \text {, } \\
\text { pentane }(13.3 \mathrm{ppb})\end{array}$ & SIFT-MS & $37 / 23$ & - & - & {$[134]$} \\
\hline \multicolumn{6}{|c|}{ Alcoholic hepatitis (AH) } \\
\hline $\begin{array}{l}\text { 2-propanol, acetaldehyde, acetone, } \\
\text { ethanol, pentane, trimethylamine }\end{array}$ & SIFT-MS & $40,40 / 43$ & $90 / 80$ & $\begin{array}{c}p \text {-value; Kruskal-Wallis ANOVA, } \\
\text { Pearson } \chi^{2}, \text { Spearman correlation }\end{array}$ & {$[135]$} \\
\hline \multicolumn{6}{|c|}{ Propionic acidaemia } \\
\hline 3-heptanone & PTR-MS and GC-MS & - & - & - & [133] \\
\hline \multicolumn{6}{|c|}{ Diabetes mellitus } \\
\hline acetone & $\begin{array}{c}\text { SPME/GC-MS, SIFT-MS, } \\
\text { laser spectroscopy }\end{array}$ & - & - & - & {$[29]$} \\
\hline acetone & e-nose, SIFT-MS & 8 & - & - & [136] \\
\hline acetone $(160-862 \mathrm{ppb})$ & SIFT-MS & - & $97.9 / 100$ & $p$-value; Non-parametric tests & {$[137]$} \\
\hline $\begin{array}{c}\text { acetone; isopropanol; toluene; m-xylene; } \\
\text { 2,3,4-trimethylhexane; 2,6,8-trimethyldecane; } \\
\text { tridecane and undecane }\end{array}$ & SPME/GC-MS & $48 / 39$ & - & PCA, OPLS-DA; MVA, Wilcoxon & {$[138]$} \\
\hline VOCs pattern recognition & e-nose & $117 / 108$ & $87.7 / 86.9$ & $\begin{array}{c}\text { k-NN voting rule to } \\
\text { classify features extracted by PCA }\end{array}$ & {$[111]$} \\
\hline
\end{tabular}


Table 1. Cont

\begin{tabular}{|c|c|c|c|c|c|}
\hline Target VOCs (Putative Biomarkers) (LODs) & Methodology & $\begin{array}{l}\text { Sample } \\
\text { (Patients/ } \\
\text { Controls) }\end{array}$ & $\begin{array}{l}\text { Sensitivity/ } \\
\text { Specificity } \\
\text { (\%) }\end{array}$ & $\begin{array}{l}\text { Statistical Approach } \\
\text { (Pre-Processing Method; } \\
\text { Classification Method; } \\
\text { Performance Measures) }\end{array}$ & Reference \\
\hline \multicolumn{6}{|c|}{ Chronic renal failure } \\
\hline NO (39 ppb) & $\begin{array}{c}\text { Ozone } \\
\text { chemioluminescence }\end{array}$ & $40 / 28$ & - & $p$-value; $\mathbf{D A} ; \underline{\chi}^{2}$ & [139] \\
\hline TMA $(0.33 \mathrm{ppb})$ & TD-GC-MS & $14 / 9$ & - & Wilcoxon & [43] \\
\hline Uraemia & IMS/GC-MS & $28+26 / 28$ & & $\frac{\text { ANOVA, two-sided two-sample Student's }}{t \text {-tests }}$ & [140] \\
\hline VOCs pattern recognition & e-nose & $110 / 108$ & $86.6 / 83.5$ & $\frac{\text { k-NN voting rule to classify features }}{\text { extracted by PCA }}$ & [111] \\
\hline \multicolumn{6}{|c|}{ Crohn's disease } \\
\hline $\begin{array}{c}\text { Set A (healthy controls/CD remission)- } 6 \text { discriminatory } \\
\text { VOCs; Set B (healthy controls/ } \\
\text { active } \mathrm{CD} \text { ); } \operatorname{set} \mathrm{C} \text { (active } \mathrm{CD} / \text { remission)- } 10 \\
\text { discriminatory VOCs }\end{array}$ & GC-TOF-MS & $725 / 110$ & $\begin{array}{l}\mathrm{A} \text { and } \mathrm{B}(96 / 97) \\
\text { C }(81 / 80)\end{array}$ & $\begin{array}{l}\text { RF to the most discriminatory VOCs } \\
\text { for the } 3 \text { groups; PCA on proximity } \\
\text { matrix obtained from the RF model. }\end{array}$ & {$[141]$} \\
\hline \multicolumn{6}{|c|}{ Helicobacter pylori infection } \\
\hline${ }^{13} \mathrm{C} \mathrm{O}_{2} /{ }^{12} \mathrm{CO}_{2}$ & $\begin{array}{l}\text { Cavity Ring-Down } \\
\text { Spectroscopy (NIR) }\end{array}$ & - & $100 / 100$ & - & [142] \\
\hline \multicolumn{6}{|c|}{ Schizophrenia } \\
\hline ethane and pentane & TD-GC-MS & $28 / 15$ & - & - & [143] \\
\hline
\end{tabular}

Abbreviations: TD-Thermal desorption, AUC - area under the curves, COPD—Chronic Obstructive Pulmonary Disease, CVV—cross-validation method, DA—discriminant analysis; FQDM—Fisher's Quadratic Discriminant Method, FT-ICR-MS- Fourier transform-ion cyclotron resonance mass spectrometry, GC/MS—gas chromatography-mass spectrometry, k-NN—k-nearest neighbour, LDA-Linear Discriminant Analysis; LOO-leave-one-out method, MCCV-Monte Carlo cross-validation, MVA—multivariate data analysis; OPLS—orthogonal PLS; PCA—principal component analysis; PLS—partial least squares; PNN—probabilistic neural network; PTR-TOF-MS - proton-transfer reaction time-of-flight mass spectrometry, PTR-MS- proton-transfer reaction mass spectrometry, RF- Random Forests, ROC—Receiver operator characteristic; SIFT-MS—Selected ion flow tube mass spectrometry, SIMCA—soft independent modelling of class analogy, SPME—solid-phase microextraction, VOCs—-volatile organic compounds, WDA—weighted digital analysis. 


\subsubsection{Real-Time Analysis}

Online real-time analysis offers several advantages as compared with indirect sampling, notably yield of immediate results and no requirement for collection and storage of samples. This eliminates a major source of experimental errors in EB analysis, particularly those related with the loss of compounds by different mechanisms (for instance, labile compounds that decompose before being analysed or compounds that change rapidly as a function of external influence [24]). Furthermore, when using MSbased methodologies, as PTR-MS, PTR-TOF-MS and SIFT-MS, it is easier to sample both the EB and the environmental air in the collection room, thus filtering from the results those arising out of exogenous contaminants [32,144]. However, direct sampling also presents some disadvantages such as high cost of acquisition and maintenance of the equipment used, particularly PTR-MS and PTR-TOF-MS. On the other hand, as pre-concentration of EB is not possible, certain low abundant VOCs cannot be detected by this approach [32,144].

\subsubsection{Proton Transfer Reaction Mass Spectrometry (PTR-MS)}

PTR-MS use in breath research is relatively recent, but very promising because it can deliver results in a real-time online analysis, with high sensitivities for VOCs detection and quantification (up to the pptv range). This analytical performance compares in terms of sensitivity (but not selectivity) with the one obtained by GC-MS (or is even greater, as shown by Bajtarevic et al. [30]). PTR-MS uses $\mathrm{H}_{3} \mathrm{O}^{+}$ ions for proton-transfer reactions with many common VOCs, while having little to no reaction with the highly abundant atmospheric gases $\left(\mathrm{N}_{2}, \mathrm{CO}_{2}\right.$ and $\left.\mathrm{H}_{2} \mathrm{O}\right)$ that compose more than $99 \%$ of EB (reviewed in $[14,73,133])$. There are, however, a few disadvantages to point to PTR-MS, namely the number of compounds that can be simultaneously analysed and the limit of detection. According to Herbig et al. [144], in an online breath analysis, a minimum of $3 \mathrm{~Hz}$ of sampling frequency is necessary in order to resolve individual breath phases. Thus, this trade-off between the number of measured $\mathrm{m} / \mathrm{z}$, and the signal-tonoise ratio $(\mathrm{S} / \mathrm{N})$, limits the number of compounds that can be simultaneously monitored and the respective limit of detection (LOD) that can be obtained. On the other hand, as the PTR-MS detection relies on the atomic mass of compounds and the resolution of quadrupole MS instruments is limited, it is impossible to identify compounds with the same molecular weight [144,145]. To overcome this sensitivity disadvantage, a TOF-MS was associated to the PTR, viz. the PTR-TOF-MS. In this technique, similarly to GC-TOF-MS, the ions are accelerated to a regular energy by an electric field. Then the ions travel a defined distance without acceleration. The $\mathrm{m} / \mathrm{z}$ will determine the time of flight of the compound. Thus, the mass spectrum can be obtained by measuring a single shot (a fraction of a second) or adding more shots (although this last option increases the $\mathrm{S} / \mathrm{N}$ (reviewed in [144]). This methodological improvement allows a three order of magnitude increment in PTR-TOF-MS and consequently it is now possible to separate distinct chemical compounds with the same molecular weight using this real-time approach ([146] reviewed in [144]). Nevertheless, as already mentioned, since pre-concentration is not possible, very low abundant VOCs can hardly be detected using this approach. Moreover, it is a far more expensive technique than GC-MS [32,144]. 


\subsubsection{Selected Ion Flow Tube Mass Spectrometry (SIFT-MS)}

SIFT-MS is a technique that combines the fast flow tube technique with MS, allowing a real-time measurement of trace concentrations of VOCs in humid air, including EB. In simple terms, EB VOCs are collected into the flow tube and ionized with precursor ions (usually $\mathrm{H}_{3} \mathrm{O}^{+}, \mathrm{NO}^{+}$, or $\mathrm{O}_{2}^{+}$), thereby forming the product ions, which are then quantified by MS. A detailed review and comparison of the methodology with PTR-MS can be found elsewhere [3,14,73].

\subsubsection{Ion Mobility Spectrometry (IMS)}

IMS was initially developed for the high sensitive detection of chemical warfare agents, illegal drugs and explosives, and adapted to industrial and environmental applications, particularly for process control in food quality analysis and air quality control. In simple terms IMS uses an external electric field at ambient pressure to separate different ions formed from the target analytes. This is achieved in different ways, using differential mobility spectrometers (DMS), high-field asymmetric waveform ion mobility spectrometers (FAIMS), homemade IMS or commercially available IMS, such as without and with different gas chromatographic columns, e.g., MCC (multi-capillary column)/IMS. Overall, the sensitivities in the ppbv- to pptv-range that can be achieved with IMS have made it suitable for breath analysis. In fact, different IMS strategies have been successfully used in the medical field, particularly in the diagnosis of several pulmonary diseases, such as lung cancer, COPD, lung infections and asthma, as well as other bacterial infections (reviewed in [74]).

\subsubsection{Targeted Breath Analysis}

Regardless of its utilization off-line and online, MS-based approaches for EB research enable a comprehensive analysis that is mandatory for the characterisation of new putative biomarkers. However, the requirement of expensive equipment and high levels of expertise to operate them constitute two important barriers to their use as POC devices. Therefore, a number of other approaches based on laser-absorption spectroscopy and chemical sensing are being developed with promising results (reviewed in $[14,75,76,81,147])$ and used in different POC devices generically known as electronic noses or "e-noses".

Electronic Noses (e-noses)

In a very recent report, Bushdid et al. demonstrated that the human olfactory system can discriminate at least 1 trillion olfactory stimuli [12]. This reveals an extraordinary in-built metabolomics in mammalians that are able to discriminate a broad range of odours by VOCs patterns. A similar approach is used in many e-nose devices. In this case, the objective is to mimic the human olfactory system in the recognition of odours as "smellprints" or VOCs patterns of different disease conditions. This is quite different of the identification and quantification of individual VOCs present in a mixture, as performed by the approaches described in the previous sections. It should be highlighted, however, that most of the first e-noses to be developed rely only in the identification of a specific compound or a class of compounds, particularly key VOCs in EB as isoprene, CO, NO, alkanes, etc. (see Table 1). Their main advantage is being POC devices suitable for an eventual utilization as medical device. Overall, e-noses use GC, IMS and MS, optical sensing or infrared spectroscopy (usually near infrared spectroscopy, NIR) and a generic 
architecture comprehending a multiple sensor array, the data acquisition system, and a pattern recognition algorithm (reviewed in [76,148]). The GC, IMS and MS approaches are based on the same principles as the corresponding bench-top technologies, but using alternative building materials and operating modes ([149-151]). The optical sensors use diverse light sources for measuring changes in a given light property when it crosses the gas mixture (reviewed in [76]). Among the optical sensors, the laser spectroscopy approach is very popular. In this case, a laser beam is used against a gas mixture, as EB samples. As many target analytes absorb in a highly specific wavelength, often referred as spectral fingerprint, the amount absorbed can be easily measured in a detector and correlated to the target analytes concentration [75]. As already referred, laser spectroscopic detection techniques are able to deliver MSequivalent high-sensitivities and selectivities, in an online and real-time fashion response and using simple and relatively inexpensive POC devices. In fact, 14 out of 35 putative breath biomarkers (acetone, ammonia, $\mathrm{CO}_{2}$, ethane, methane, and $\mathrm{NO}$, among others) have been already analysed by laser spectroscopic techniques (reviewed in [75]). The application of these e-nose solutions to large populations is much easier than a comprehensive study using MS detection and certainly the data obtained would be very relevant. Nevertheless, there are a number of issues that have to be solved before e-noses can reach a level to be used in medical diagnosis (reviewed in $[7,152,153]$ ).

\section{The Metabolics of EB Volatiles}

Every disease has associated alterations in the normal physiology and metabolism and are characterised by some changes at the level of gene regulation, proteins expression and metabolites production. Some of these changes can be disease specific and hence could be used as "biosignatures" for those diseases. In this sense, the occurrence of certain VOCs in EB as a result of alterations in various metabolic pathways can distinguish a disease state from a healthy state. These volatile metabolites are majorly consisting of inorganic gases, like nitric oxide (NO) and carbon monoxide (CO), and VOCs as hydrocarbons (pentane, ethane and isoprene), oxygen-containing compounds (acetone, acetaldehyde, methanol, ethanol, and 2-propanol), sulphur-containing compounds (dimethylsulfide, methyl, and ethyl mercaptanes), and carbon disulfide and nitrogen containing substances like ammonia and dimethyl/trimethylamine (reviewed in [154]). Overall, these and other VOCs allow insights into different biochemical pathways involved in various diseases and sometimes are even considered as putative biomarkers of those diseases. In this section we will address the possible biochemical metabolic mechanisms of most frequent VOCs reported in EB. In the end, we will explore the potentialities of breath analysis in the diagnosis of different diseases (Table 1).

\subsection{Hydrocarbons}

\subsubsection{Saturated Hydrocarbons}

Lipid peroxidation is a hallmark of several diseases and clinical conditions, such as cancer, inflammatory diseases, atherosclerosis, and aging [31] and hydrocarbons, such as ethane and pentane, are the end products of this highly deleterious reaction. Lipid peroxidation is a chain reaction triggered by removal of allylic hydrogen atoms upon reactive oxygen species (ROS) attack. This results in the formation of very reactive peroxides that participate in further oxidative reactions, particularly against 
lipids of the cell membrane, viz., $\omega 3$ and $\omega 6$ fatty acids. As a result, saturated hydrocarbons, such as ethane and pentane, are generated from $\omega 3$ and $\omega 6$ fatty acids, respectively [154]. Malondialdehyde (MDA), another aldehyde, is also formed in the same pathway. Both in vitro and in vivo studies have shown a very similar pattern in diseases involving high peroxide activity and release of ethane and pentane [155]. Therefore, these aliphatic hydrocarbons are considered as biomarkers for both in vitro as well as in vivo lipid peroxidation processes [155]. And although these VOCs can be generated by some colonic bacteria via metabolism and protein oxidation, their contribution does not correlate with the EB assessment for ethane and pentane under situations in which high oxidative conditions are present [156]. Nevertheless, there are some additional metabolic considerations for ethane and pentane. The physiological ratio of $\omega 3$ and $\omega 6$ fatty acids is in such a way that the amount of pentane that results from lipid peroxidation is four times higher than ethane. Pentane, however, is easily metabolized by cytochrome P450 enzymes present in hepatocytes [157]. Therefore, in the interpretation of EB pentane concentration, a situation of liver function variability has to be carefully taken into consideration during the sampling period and between the patients. In a study by Dryahina et al. on inflammatory bowel disease, pentane was found to be significantly elevated in the breath of both the Crohn's disease and ulcerative colitis patients as compared to the healthy individuals [158]. Overall, pentane and ethane abundances are increased in inflammatory diseases [154] as well as in lung cancer [75]. Hydrocarbons are stable end products of the process of lipid peroxidation and have low blood solubility as a result of which they are diffused into the breath within a few minutes of their generation inside the tissues. Therefore, the concentration of exhaled ethane and pentane can become a useful monitoring approach for the extent of oxidative damage in the body $[159,160]$. Regarding this, Ross et al. used breath ethane and pentane to show that unmedicated patients with schizophrenia already exhibit elevated levels of oxidative stress and this is not a consequence of the medication these patients usually take [143]. Data about other saturated hydrocarbons is scarcer. Propane and butane, for instance, seem to be exclusively formed by protein oxidation process and gut flora and their importance as markers of lipid peroxidation is unclear [154]. In turn, Bos et al. reported an increased concentration of octane (together with acetaldehyde and 3methylheptane) in Acute Respiratory Distress Syndrome (ARDS) [118].

\subsubsection{Unsaturated Hydrocarbons}

Isoprene

2-methyl-1,3-butadiene commonly known as isoprene (unsaturated hydrocarbon) is a major constituent of EB [161], being easily detectable at ppb range [162-164]. There is little information available about the biochemical source of isoprene, although it is known that the compound has an endogenous origin [77,161,165-170], and it is not a product of the airways [171]. A growing number of evidences pointed out isoprene as a by-product of cholesterol biosynthesis along the mevalonic acid pathway [166-168,172-177]. One of the key steps for the cholesterol biosynthesis is the synthesis of mevalonic acid from acetic acid [174] which is a rate limiting step for the synthesis of sterol and is catalysed by hydroxymethylglutaryl coenzyme-A (HMG)-CoA. Mevalonic acid is further transformed into isopentenyl pyrophosphate inside the cytosol, which further goes through isomerization to form dimethylallyl pyrophosphate (DMPP) [178]. With the help of a carbonium ion intermediate generated 
in the previous steps, DMPP is quickly converted to isoprene by an acid-catalysed elimination reaction in liver cytosol [167]. It is still unknown whether this particular non-enzymatic reaction actually results in the formation of isoprene under the physiological conditions. In some plants, this reaction (the production of isoprene from DMPP) is catalysed by a $\mathrm{Mg}^{2+}$ containing enzyme [176]. Therefore it is possible that a similar enzyme may be responsible for catalysing the isoprene conversion from DMPP in the mammalian tissue. The candidate is the $\mathrm{Mg}^{2+}$-dependent isopentenyl pyrophosphate isomerase. The involvement of isoprene cholesterol metabolism is further supported by the observation that there is a simultaneous decrease in isoprene secretion and sterol synthesis upon the administration of lovastatin, a lipid-lowering drug. This strongly suggests that isoprene found in breath is derived from the cholesterol synthesis pathway in humans. Moreover, the administration of Lovastatin to healthy individuals and ICU (intensive care unit) patients showed a proportional decrease in isoprene as well as plasma total cholesterol concentrations [174]. Additionally, a cholesterol-rich diet is also responsible for decreased levels of isoprene in exhaled breath [174] because of the feedback inhibition of HMG-CoA reductase (3-hydroxy-3-methyl-glutaryl-CoA reductase) [179,180]. Isoprene concentrations correlated with cholesterol biosynthesis $[75,154]$ and hence the monitoring of breath isoprene may be helpful as a marker for the lipid and cholesterol status monitoring and even in analysing the efficiency of lipid-lowering therapy. There is, however a strong positive correlation between muscle activity and isoprene [181,182] and this constitutes a major confounder for any correlation with cholesterol metabolism. Nevertheless, Isoprene has also been studied in other diseases. In lung cancer, isoprene shows a decreased concentration [30]. In another study on lung cancer patients, breath isoprene levels correlated quite significantly with increased total cholesterol and LDL, although no significant relationship has been observed between isoprene and HDL, triglycerides and C-reactive protein [183]. Breath isoprene is both age dependent, with males typically presenting higher levels than females, and affected by a circadian rhythm with levels peaking between 2 AM. and 6 AM (reviewed in [29]). Overall, it is widely accepted that breath isoprene reflects the rate of cholesterol production, although there are not enough studies to verify this correlation with the degree of cholesterolaemia and evaluate the interference of the contribution of muscle activity for isoprene levels.

\subsection{Ketones}

\subsubsection{Acetone}

Acetone is one of the most notable ketone produced by the human metabolism and also a major constituent of human breath. Different mechanisms can lead to its formation. It is absorbed in the body from exogenous sources of contamination, such as food, effluents from chemical industries. Endogenously, acetone can be produced in the hepatocytes through the decarboxylation of excess Acetyl-CoA (Figure 3), but any metabolic change involving an increase in fatty acid oxidation (exercising, fasting, food consumption, weight loss, cancer, and also protein metabolism) results in the formation of ketone bodies, like acetoacetate, $\beta$-hydroxybutyrate and acetone. In turn, the spontaneous decarboxylation of acetoacetate can also yield more acetone. Remarkably, acetone is the ketone body produced in smaller quantities. Its higher volatility, however, make it easily detectable from breath, urine and skin. In the uncontrolled diabetes mellitus patient's breath, for instance, acetone concentrations are particularly 
elevated, constituting an easy way to assess the treatment success and a supporting disease monitoring approach, when combined with the regular glucose level checking [184-186]. In this context, Wang et al. also reported that patients with type 1 diabetes have excess acetone in their breath [75]. In turn, Storer et al., studied type 2 diabetic patients undergoing a long term dietary modification programme and observed that breath acetone concentrations vary between 160 and 862 ppb [137]. Nevertheless, acetone can not be considered as a marker of diabetes mellitus, but instead of ketone bodies formation. In turn, ketone bodies are a measure of blood glucose levels. Acetone variations have been described in many other diseases and clinical conditions. Alkhouri et al., for instance, studied overweight and obese children with Non-Alcoholic Fatty Liver Disease (NAFLD) and found many VOCs, including breath acetone, in significantly higher concentrations [134]. In another study, on liver disease, Hanouneh et al. were able to distinguish between patients with Alcoholic Hepatitis (AH), acute decompensation and individuals without liver disease using several breath metabolite levels, mainly breath acetone [135]. Marcondes-Braga et al. found higher EB acetone concentrations in Heart Failure (HF) patients as compared to healthy control volunteers. In this study, they exhaustively monitored the condition of HF in a large sample size and reported breath acetone as a new biomarker of HF severity [132]. Overall, given the several sources and situations that can lead to an increase in the concentration of EB acetone, this ketone can hardly be considered as a biomarker of a particular disease or clinical condition. Nevertheless, taking together with additional parameters, it provides very relevant information about the human metabolism.

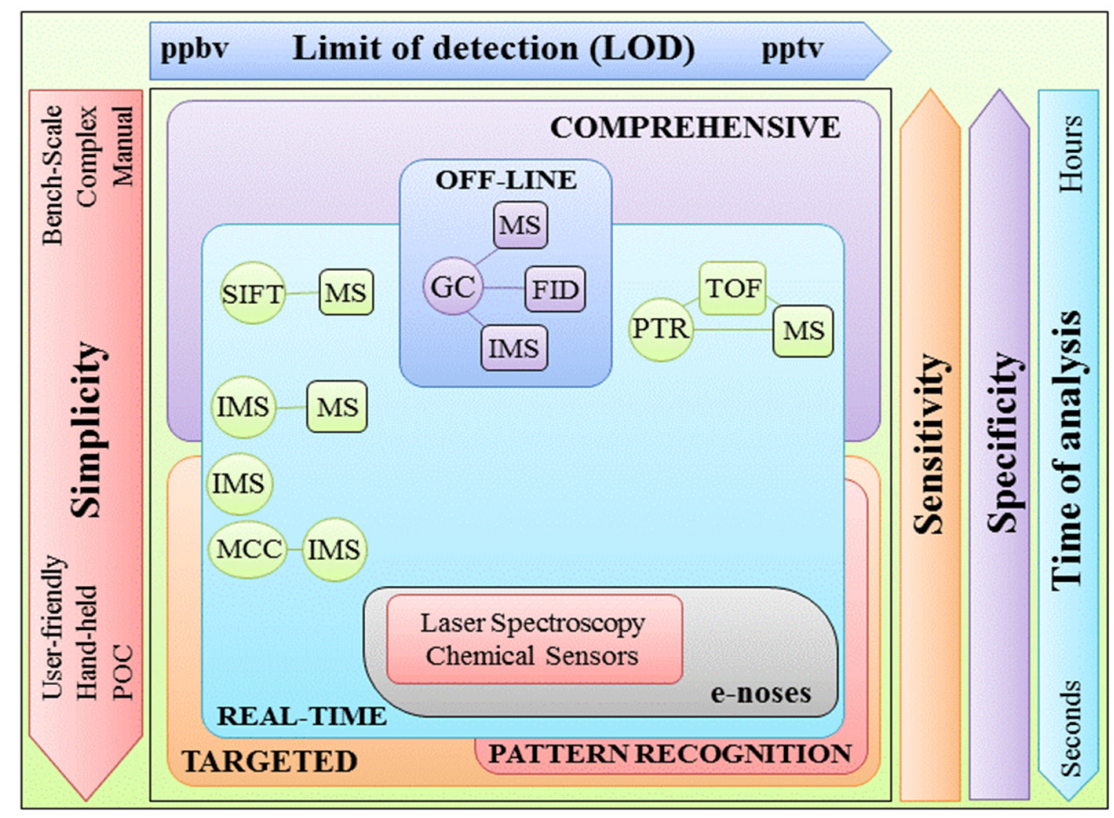

Figure 3. Overview of the methodologies most used in exhaling breath (EB) analysis and comparison of some analytical features, as limits of detection, sensitivity and specificity. Additional inputs as time of analysis and simplicity are also included. Abbreviations used: FID - flame ionization detection; GC — gas chromatography; MCC-IMS - multi capillary column ion mobility spectrometry; POC — point of care; PTR-TOF-MS — proton transfer reaction with time-of-flight mass spectrometry; SIFT-MS — Selected ion flow tube mass spectrometry. 


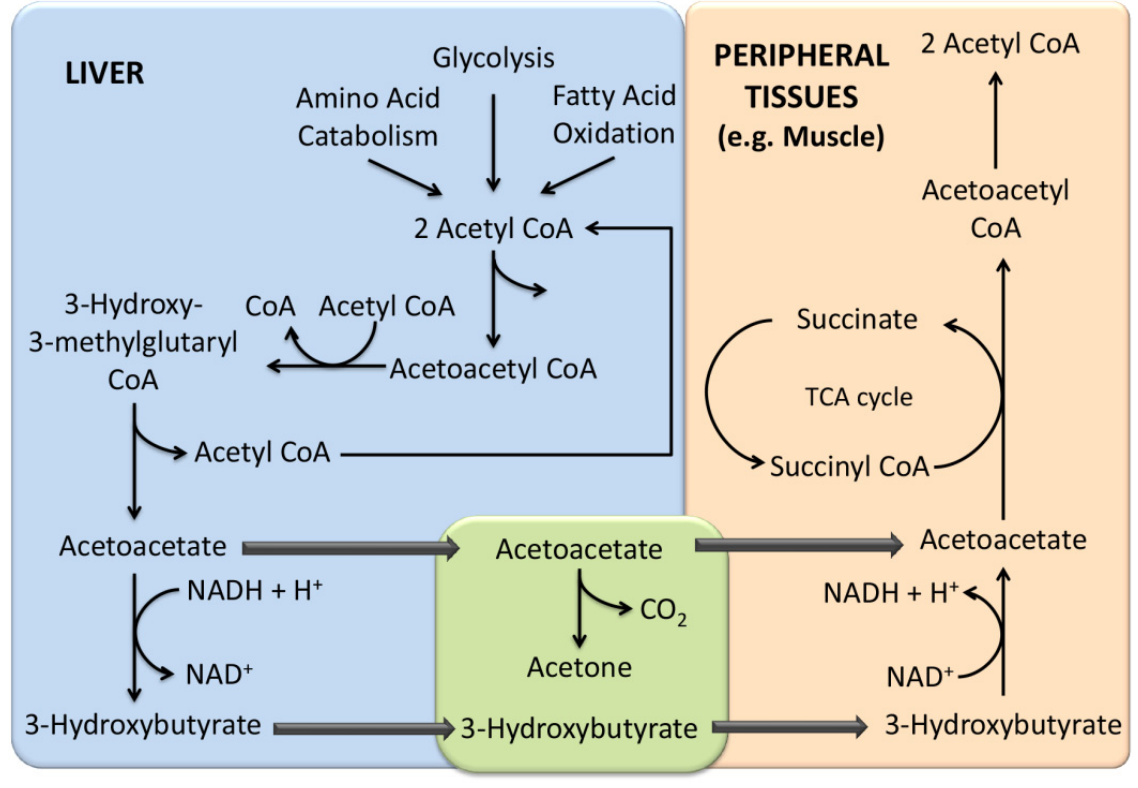

Figure 4. Metabolism of acetone and its precursors in liver and muscle.

\subsubsection{2-Butanone}

2-Butanone is an important ketone, being widely used as a raw material in different industries, such as the paints, coatings, resins, and printing industries. For a long time it has been associated with some toxicity, but since 2005, it has been reclassified as a non-hazard air pollutant [187]. 2-Butanone occurs naturally in the environment, although in negligible levels when compared with its industrial demands, being secreted from many different species of bacteria, fungi, and plants ([188-194]). Remarkably, it was recently shown to elicit induced acquired resistance in the cucumber against two natural predators [195]. 2-Butanone seems to be ubiquitously present and has been detected in several human fluids of apparently healthy volunteers, including skin emanations, saliva, urine, faeces, blood and exhaled breath ([196-199]). In a recent review about lung cancer VOCs and their possible biochemical pathways, Hakim et al. classified 2-Butanone as dietary and environmental contaminant [16]. However, several other studies reported the augmented presence of 2-Butanone in the breath of patients with different diseases conditions, including liver cirrhosis [5], lung cancer [87,200,201], ovarian cancer [202], H. pylori infection [203] and sepsis [204]. Moreover, Fu et al., were able to discriminate lung cancer patients in different stages through 2-butanone, showing that its concentrations were significantly higher in the exhaled breath of non-small cell lung cancer (NSCLC) patients in stages II though IV when compared to with stage I [39].

\subsection{Nitrogen Containing Compounds}

\subsubsection{Nitric Oxide (NO)}

NO is the most important nitrogen compound in terms of volatile EB biomarkers, being produced by different types of cells in the respiratory tract, such as inflammatory, epithelial, and vascular endothelial cells and airway nerves [205]. NO has one unpaired electron, which makes it highly reactive towards 
other molecules. It has a half-life of around 1-5 seconds and diffuses freely across membranes. These properties make NO an important transient signalling molecule working both within a single cell (autocrine) and between adjacent cells (paracrine) [206]. In fact, NO modulates the endothelium vasodilatation activity and for this reason is also termed as the endothelium-derived relaxing factor, EDRF. It is used by the cells to send signals to the surrounding smooth muscle to relax, thereby, causing vasodilation and blood flow increase. This physiological activity is influenced by several factors, as the levels and activity of the enzymes involved in NO production, its uptake rate by antioxidant molecules (glutathione and haemoglobin, for instance), and the levels of oxidative stress [207]. Additionally, NO can be generated in the phagocytes (macrophages, neutrophils, and monocytes) that use it against pathogens (human immune response). Phagocytes express an inducible NO synthase (iNOS) that is regulated by interferon-gamma (IFN- $\gamma$ ) and tumour necrosis factor (TNF) (activators) [208-210], transforming growth factor-beta (TGF- $\beta$ ) (strong inhibitors) and the interleukin-4 (IL-4) and IL-10 (weak inhibition). This tight regulation of iNOS reflects the importance of NO in inflammation and immune responses [211]. In fact, NO is distinctively observed in the bronchial system and is reported to be a marker for airway inflammation [154]. This assumption results from extensive studies in different lung diseases, particularly those in which NO metabolism is altered. Regarding this, Ghosh et al., for instance, suggested that high NO levels are present in the asthmatic airway environment, which is oxidative in nature. This further leads to an increase in the generation of reactive nitrogen species (RNS) and consequent protein nitration and oxidation. Ultimately, these modifications adversely affected protein functions, contributing to chronic inflammation [212]. Therefore, NO, through the measurement of its fractional concentration in exhaled breath (FENO), has become an important example of an exhaled biomarker that has reached clinical practice, particularly in the management of asthma [213,214]. This pulmonary complication is characterised by recurrent and reversible airflow obstruction with different degrees of severity [215] and FENO helps not only in its diagnosis, as well as in the discrimination of its phenotypes and treatment monitoring, [216,217], being a surrogate marker of eosinophilic airway inflammation and good predictor of corticosteroid response [218]. Overall, FENO constitutes a valuable diagnostic tool for a reliable clinical guidance in asthma treatment, particularly when its values are low [219]. Consequently, several devices using chemiluminescent and electrochemical sensors able to accurately measure FENO are already present in the clinical environment and other approaches, using quantum cascade lasers, for instance, are being developed [220,221]. Chronic obstructive pulmonary disease (COPD), is characterised by a generalized inflammation that causes airways obstruction and, consequently, breath shortness [222]. In this case, NO has been correlated to the severity of COPD and higher levels are found in unstable COPD patients [223]. Similarly, promising FENO discriminative variations between patients and controls are observed in other complications besides COPD and asthma, including cystic fibrosis (CF), systemic sclerosis, hepatopulmonary syndrome and primary ciliary dyskinesia [224,225]. Additionally, Fisher et al. also reported increased exhaled NO levels in lung-transplant recipients with lymphocytic bronchiolitis and early obliterative bronchiolitis [226]. These findings suggested a possible role for exhaled NO also as a marker of pulmonary allograft dysfunction (reviewed in [14]). FENO can become also a useful diagnostic tool in several non-pulmonary diseases, namely CVDs. In this context, Baylis reported that the overall NO production is reduced in chronic kidney disease (CKD), promoting cardiovascular deleterious modifications and further kidney damages [227]. Using an ozone chemiluminescence technique, Matsumoto et al. also found higher exhaled NO concentrations in chronic renal failure patients [139]. In 
turn, Huang et al. reported for the first time the presence of exhaled NO along with other metabolites in the exhaled breath condensate (EBC) of Paediatric Inflammatory Bowel Disease (IBD) patients [228].

\subsubsection{Dimethylamine (DMA) and Trimethylamine (TMA)}

The higher levels of nitrogen containing compounds, such as DMA and TMA, are the cause of the distinctive odour of the breath of uremic patients. The identification and quantification of these amines was carried out way back in early twentieth century, when a study with chronic kidney disease patients showed that the occurrence of TMA in their breath could be considered as a potential marker of renal disorder, previously detected in plasma [43]. In uremic breath patients, ammonia also has a distinctive presence. In normal conditions, ammonia is eliminated via conversion to urea, but in the presence of liver function abnormalities, this elimination is not totally fulfilled and higher levels of ammonia remain in the blood. As ammonia is highly volatile, it can be then easily detected in these uremic patients breath [229].

\subsubsection{Acetonitrile (ACN)}

One of the most important nitrile compounds in human breath is $\mathrm{ACN}$, which is a key component of tobacco smoke. This has been shown in several studies reporting the higher breath ACN concentrations in smokers as compared with non-smokers [84,87]. A similar observation was also reported in lung cancer patients who were ex-smokers when compared with lung cancer smokers [30] and healthy smokers [87]. The pathway behind ACN metabolism is its biotransformation by cytochrome p450 monooxygenase to cyanohydrine, and its further spontaneous decomposition into hydrogen cyanide and formaldehyde. ACN metabolism, as reported by Li et al. [230] is quite slow, hence a significant part is excreted as ACN in the EB and urine [231]. These authors used Extractive ElectroSpray Ionization Mass Spectrometry (EESI-MS) to follow EB ACN concentration in active and passive smokers, and non-smokers. They concluded that the concentrations of EB ACN increases continuously for $1-4 \mathrm{~h}$ after the smoker finished smoking and then slowly decreases to the background level in 7 days [230].

\subsection{Aldehydes}

Aldehydes participate in the human metabolism through different forms, being involved in signal transduction, gene regulation, and cellular proliferation, although some of them are cytotoxic intermediates [232,233]. These compounds can be generated in the body through various mechanisms, though metabolic conversion of alcohols being their major source (reviewed in [234]). Another mechanism for aldehydes generation is the reduction of hydroperoxide by cytochrome $\mathrm{p} 450$ as a secondary product of lipid peroxidation. The hydroperoxy bond undergoes a stepwise one-electron reduction, in which the first reductive step yields an alkoxy radical. This radical undergoes the well-known $\beta$-scission reaction to yield a ketone or an aldehyde and a derived radical, $\mathrm{R}^{\prime *}$ [235]. The endogenous production of aldehydes can be also caused by the smoking habit, that generates both saturated compounds, such as formaldehyde, acetaldehyde, propionaldehyde, butyraldehyde, and unsaturated compounds, such as acrolein and crotonaldehyde [236]. Additionally, smoking can generate aldehydes inside the body as by-products of tobacco metabolism mediated by cytochrome P-450 during the detoxification process [237]. Regarding this, 4-(methylnitrosamino)-1-(3-pyridyl)-1-butanone(NNK) is a major constituent of tobacco smoke and a known 
carcinogenic agent (a detailed mechanism of NKK carcinogenic effects can be found elsewhere [238-240]). Overall, regardless of the specific mechanism involved in their formation, many aldehydes have been described as promising biomarkers in different diseases, as reported, for instance, by Fuchs et al. studying lung cancer patients [85].

\subsubsection{Formaldehyde}

Formaldehyde is metabolized from methanol by the enzyme alcohol dehydrogenase (ADH), which is also involved in ethanol conversion to acetaldehyde. The same enzyme can then oxidize these endogenous aldehydes, yielding carboxylic acids. Wehinger et al. reported higher formaldehyde concentration in the breath of lung cancer patients compared to healthy individuals [84]. The same study supported the finding that formaldehyde is generated by lung cancer and immune cells, while tryptophan degradation is taking place during metabolism [241] resulting in the impairment of the function of immune system during carcinogenesis $[242,243]$. In another study involving lung cancer patients, healthy smokers and healthy non-smokers, formaldehyde concentration was found elevated in lung cancer patients and healthy non-smoker breath as compared to healthy smoker breath [85]. Finally, formaldehyde has also been reported to be augmented in breast cancer patients [75]. Formaldehyde has a high solubility in water and is almost entirely absorbed in the respiratory system when inhaled from the environment. To cope with its toxicity, the formaldehyde dehydrogenase (FDH, an ALDH of the respiratory tissues), oxidizes formaldehyde after binding to glutathione (GSH), forming the adduct S-hydroxymethylglutathione.

\subsubsection{Hexanal and Heptanal}

Hexanal and heptanal are another two aldehydes observed in urine, breath, and blood samples of lung cancer patients $[85,102,244]$. Their levels were also reported to be augmented in patients with stage I Non-Small Cell Lung Carcinoma (NSCLC) $[82,85,244]$. Further comparison of their breath and blood concentrations, suggested that breath hexanal and heptanal are originated from blood. Therefore, hexanal and heptanal breath screening for lung cancer seems very promising and must be further investigated [244]. Finally, in another study using breast cancer patients, four aldehydes (hexanal, heptanal, octanal, and nonanal) were found to be in significantly higher concentrations when compared to healthy individuals [102].

\subsection{Potential Use of Breath Analysis in Different Diseases}

In this section we briefly discuss current trends in disease diagnosis using EB analysis. Table 1 gives the examples of EB VOCs that form putative biomarkers for different diseases. The suitability of breath analysis for disease diagnose depends firstly on its discriminatory ability to classify patients according to the diseases affecting them. Therefore, the sensitivity and specificity of the methodology has to be robust and there should be very limited number of false negatives and false positives otherwise lives can be in danger due to unnecessary medical treatments and interventions respectively.

\subsubsection{Oncologic Diseases}

Lung cancer (LC) is the leading cause of cancer mortality, accounting for $28 \%$ of the cancer related deaths $[30,82,245]$. The National Lung Screening Trial (NLST, USA) demonstrated that LC screening 
by low dose computed tomography (LDCT) scans reduced the lung cancer mortality rate by $20 \%[39,82]$. Currently, CT and bronchoscopy are the principal techniques used for lung cancer detection [39]. The diagnosis of early stage lung cancer is critical for the life expectancy of the patients as its five-year survival is around $58 \%-73 \%$ when lung cancer is diagnosed in stage I, but drops abruptly to only $3.5 \%$ for later stages diagnosis. Taking in account that only $15 \%$ of lung cancer cases are diagnosed at an early stage, more than half of lung cancer patients die within the first year of upon the diagnosis [245]. The main cause for this is that available diagnostic methods are not sensitive enough and, moreover, they are expensive and invasive. Also for this reason, prescription of these methods for diagnosis often happens during late stages of the disease $[30,245]$. There are strong evidences suggesting that certain cancers can be detected by molecular analysis of exhaled air [30] and for that reason exhaled VOCs are promising candidates as LC biomarkers. These VOCs are emitted from the membrane of the cancer cells and/or from the surrounding microenvironment to the blood stream [16,82]. The cancer-related changes in the blood chemistry are then reflected in measurable changes to the breath through excretion via the lungs [82]. Previous studies have shown that the breath VOC profile of LC patients differs from healthy subjects. The results of these studies indicated that the breath test might have future potential for the management of patients with pulmonary nodules [82,245]. In fact, monitoring VOCs in the breath may rapidly become an interesting addition or an alternative to conventional medical diagnostics. This innovative approach could transform LC care and management by allowing non-invasive diagnosis, prediction of the metastatic potential of the cancer cells, adapting individual treatment, and monitoring therapeutic success [16,246]. Table 1 gives several examples of EB studies applied to lung cancer using different approaches, including GC [85-87,97], PTR-MS [30,84] and several e-nose and sensor devices [82,88-96,98]. It is noteworthy to mention here that the colorimetric sensor array developed by Mazzone et al. detects volatile, active compounds present in the EB of LC patients [91,94]. Colorectal cancer (CRC) is the second leading cause of cancer-related death in Europe and the third in the USA. The search for new and non-invasive screening system with the potential for high patient compliance and of low cost is still continuing (reviewed in [247]). Two promising studies, however, should be mentioned: Altomare et al. compared EB samples from CRC and healthy patients using GC-MS and identified 15 discriminating VOCs [27]. In turn, Peng et al. analysed EB samples from patients affected by several forms of cancer using GC-MS and a custom nanosensor array. They were able not only to discriminate between cancer patients and healthy controls (GC-MS), but also between different forms of cancer (CRC, breast, lung and prostate cancers) [101].

Gastric cancer is one of the most common causes of death from cancer worldwide. The lack of defined risk factors and the unspecific clinical symptoms often delay its diagnosis, leading to a poor prognosis and high rates of recurrence. The usual technique for diagnosing gastric cancer is the upper digestive endoscopy combined with biopsy and histopathological evaluation of the biopsy samples. However, this method is invasive, relatively expensive, and requires highly skilled medical staff. Therefore, it is necessary to find a simple and non-invasive alternative to this screening test. A pilot study from $\mathrm{Xu}$ et al. using a nanomaterial-based breath test identified several VOC differentially present in the EB of gastric cancer patients [105].

Breast cancer $(\mathrm{BC})$ is the most prevalent form of cancer diagnosed in women [248]. Its early diagnosis is very important to reduce the $\mathrm{BC}$ mortality rate, but the conventional methods (mainly echography, $\mathrm{X}$-rays and tissue biopsies) are expensive and uncomfortable and invasive for the patient. EB analysis is 
a promising approach for the early BC diagnosis, but a limited number of studies have been performed to support it [99-104].

\subsubsection{Pulmonary Diseases}

Lung cancer is certainly one of the most important pulmonary diseases to study, but there are several other pulmonary complications that have been assessed using EB analysis. This include, for instance, airways inflammation [111], asthma [112-117], acute respiratory distress syndrome (ARDS) [118,119], pulmonary embolism [120], chronic obstructive pulmonary disease (COPD) [124-128], pulmonary tuberculosis [121-123] and cystic fibrosis (CF) [129-131]. Asthma is an inflammatory disease of the airways and the most prevalent chronic illness in childhood. It's diagnose is invasive, requiring the collaboration of the patient and therefore its reliability, although high in adults, is very poor in children. Therefore it is very relevant to highlight here the recent work from Smolinska et al. that used breath analysis to characterize early predictive signatures of asthma in preschool children (2-6 years) [117]. Their work is particularly interesting because there isn't available any reliable methodology that can be used on children with confounding symptoms (transient wheezing, cough and difficulties in breathing) and discriminate such children from those who would develop asthma [117]. Another pulmonary complication, pulmonary tuberculosis, is becoming a serious health problem, particularly in the developing countries. The common methods used in the screening of this disease are sputum smears and chest radiographs. These approaches are highly specific for active pulmonary tuberculosis, but their value in primary screening is limited by its low sensitivity and high cost. Breath VOCs might provide new biomarkers for active pulmonary tuberculosis, since, for instance, patients suffer from increased oxidative stress which creates distinct VOCs patterns [121]. Nevertheless, oxidative stress is a hallmark of all inflammatory processes and so additional specific VOCs for tuberculosis diagnose must be found. CF is characterised by a chronic airway inflammation, retention of viscous secretions, bronchiectasis and, often, bacterial infection [129,249]. Most treatment decisions continue to be based on clinical judgement and secondary parameters that derive from pulmonary function testing, chest radiography or blood analysis. Bronchoscopic lavage or biopsy can be applied in the evaluation of inflammatory processes, but risks associated to this invasive medical procedure are often unjustified [129]. Therefore, it is necessary to find biomarkers of inflammation in order to monitor disease progression.

\subsubsection{Other Diseases}

Several VOCs can be linked directly to cholesterol metabolism, as isoprene. Therefore, its measurement in EB can be used to monitor cholesterol metabolism [29] and eventually cardiovascular diseases (CVDs). Acute decompensated heart failure (ADHF) is the most common cause of hospitalization, especially at the elder age. However, the identification of the individuals with imminent decompensation using the conventional clinical methods is unreliable. Some studies have reported elevated levels of acetone, pentane, and NO in the exhaled breath of heart failure patients suggesting the viability of the exhaled breath analysis in ADHF [28,132]. EB analysis has also been used to assess chronic renal failure $[43,111,139,140]$. Pagonas and his colleagues, for instance, using IMS followed by GC-MS, identified VOCs that are retained in uraemia and observed significant differences between patients with and without renal failure [140]. This result indicates the possible use of breath analysis as a screening 
method for renal failure. This is particularly interesting for paediatric care due to its non-invasive nature. Additionally, it may be used for real-time monitoring of haemodialysis efficacy [140]. In liver diseases, breath analysis has been used to study hepatocellular carcinoma [108-110], cirrhosis [5], non-alcohol fatty liver disease (NAFLD) [134] and alcoholic hepatitis (AH) [135]. Recently, it was also possible to distinguish the breath of patients with Crohn's disease and patients with active ulcerative colitis, using GC-TOF-MS [141]. Using SIFT-MS, EB pentane was shown to be a putative biomarker of bowel disease [158]. In this case, however, the discriminative ability of pentane as a biomarker of bowel disease should be very limited as alkanes, namely pentane and ethane, are two very promising biomarkers of oxidative stress (reviewed in [182]), which in turn is a hallmark in several diseases, including cardiovascular, oncologic and neurodegenerative diseases. Another very relevant work reports an e-nose composed by an array of sensors for different EB compounds that was able to discriminate patients with diabetes, airways inflammation and chronic renal disease with promising results [111].

\section{Data Analysis and Discriminatory Models Used in Breath Biomarker Research}

The ultimate goal of breath analysis utilization in disease diagnosis, is to identify a set of VOCs that show statistically significant variation between patient and control samples. However, discovery of such a set of discriminatory VOCs suffers from some practical challenges and bottlenecks. Nevertheless many putative biomarkers have been reported from breath analysis studies even though many of these biomarkers have failed to yield reproducible results by studies made elsewhere [250,251]. A look into the breath analysis literature reveals a set of challenges and bottlenecks and they are as follows: (a) the data produced in breath analysis are biologically complex and are very large in size; (b) the data contain several sources of variance, which include information of interest, but also irrelevant variance associated with biological variation or noise [252]; (c) reported studies have very often used insufficient number of patient and control samples as compared to the large number of VOCs measured [251] which results in false positive correlations (the voodoo correlations, reviewed in [253]) and (d) many of the studies suffered from confounding variables and statistical misconceptions [251,253]. Hence, the choice of an appropriate statistical method, or data visualization tools, for detection of significant trends, correlations and, eventually, biomarkers is an important step in data mining [178]. Nevertheless, before the true statistical analysis, several important steps must be followed in order to improve the reliability of the results.

\subsection{Data Pre-Processing and Normalization}

Data pre-processing is the initial treatment of the raw data obtained after sample analysis and include several sequential paths: denoising and baseline correction, samples alignment, peak picking and merging and data matrix assembly [252]. Denoising, also known as smoothing, is the reduction of the noise introduced by random variations due to instrumental conditions. Similarly, the baseline correction is the correction of the background of the chromatogram. The next step is the alignment of all samples, which is necessary to reduce the distortions in retention time produced by variations in instrumental conditions (e.g., variation in temperature, column). The peak picking and merging data matrix assembly is necessary to obtain greater reliability in the results [252]. This is performed by finding all local maxima and associated local minima for each peak, as well as $\mathrm{S} / \mathrm{N}$ determination. Therefore, peaks are only considered if they have $\mathrm{S} / \mathrm{N}$ above a given threshold (taking into account standard deviation of the 
signal). Following this, an automated peak matching, based on the spectral signature, enables the representation of each VOC as a single number in the data matrix across all measured samples. The resulting data can be therefore represented as matrix whose rows are the observations and columns the relative VOCs amounts [252]. Data normalization is, particularly, an important step to simplify the statistical analysis. Typically, a normalization factor, as total area, is applied to all samples in the assumption that the total area is constant between samples, and the total profile is directly proportional to the total concentration of the sample. Other methods can be used in order to normalize the results, such as the total sum normalization, which uses the inverse of the total area aggregating normalization, known as "histogram" normalization. A detailed review about this issue can be found elsewhere [252]. As already mentioned breath analysis involves huge number of VOCs accompanied with an inherent noise. It is therefore pertinent choose a limited number of VOCs before they are developed as biomarkers. As a starting point, this selection should involve the VOCs that show highest variance or those that are mostly associated with patient sample set [179].

\subsection{Data Analysis}

Traditionally, researchers used $p$-values as a guide to identify VOCs that show statistically significant variation between the patient and control sample. However, $p$-value usage is very limited and if determined using a wrong statistical treatment may lead to false positives and negatives. Particularly, the $p$-value $<0.05$ that is very often used, is not the most appropriate threshold for studies involving multiple hypothesis testing, leading to the detection of false positives [251]. Therefore, a more stringent threshold value with Bonferroni correction has been recommended [251]. Nevertheless, multivariate statistical analysis seems much more suitable to find a set of biomarkers for many different diseases and this assumption is nowadays widely consensual [252-254]. This can be done in an unsupervised and supervised approach. Normally, unsupervised analysis is the first approach applied in the data generated after sample analysis. It allows data exploration in order to find biological changes between the study groups. The most common method used is the Principal Component Analysis (PCA), which essentially does a reduction in the multidimensional data. However, it does not provide information regarding the variable responsible for the clustering and the outliers are a major concern [252]. Another method used is the clustering, which is a data mining technique to make automatic data groupings according to their degree of similarity. There are different clustering approaches, of which $k$-means is very often used [255,256]. However to deal with many outliers and complex data sets, more robust and sophisticated approaches should be used, as distribution-based (e.g., Gaussian mixture models [252]) or graph-based clustering methods (spectral or transitivity clustering [252,257]). The unsupervised methods are popular for data visualization but very limited to develop a classification model (do not allow data classification). Therefore, unsupervised methods are usually followed by the supervised methods which allow the characterisation of the relation between a matrix of predictors (in this case VOCs) and vector (or matrix) of responses (e.g., class membership) [252]. To achieve this, linear or nonlinear statistical techniques can be applied, according to the purpose of the analysis. In the first case, the linear discriminate analysis (LDA) is the most often used in breath analysis. Its objective is discovering a linear function based on the original compounds founded, in order to distinguish between the studied groups (e.g., control and disease groups) [258]. LDA is a fast and powerful technique, requiring few optimizing operations, but it 
can be only applied when there are more samples than the variables [259]. This is, however, the opposite of the most frequent situation in breath analysis and thus PCA is previously used for dimensionality reduction and only then LDA can be applied for classification purpose [252]. Partial least-square (PLS) was originally developed for the quantitative analysis in regression problems [260], but its ability to cope with highly collinear data made it also very suitable for breath analysis [261]. Using this method, it is possible to distinguish the studied classes and to find which compounds are responsible for each of them [252]. PLS-DA is another important method for samples classification. It requires some model optimization, as it frequently causes data overfitting, but it is advantageous in the fact that its model precision improves as the number of relevant variables increases [262]. Metabolomics data frequently show non-linear patterns, but these problems are well handled by using non-linear methods. There are many non-linear methods available, but the most often used are the Kernel-based models (as the support vector machine (SVM) and kernel-PLS-DA [263]), and artificial neural network (ANNs) ([264,265]). SVM method is primarily a binary classification method and in simple terms it converts the data via specific functions called kernels, to obtain a big map of nonlinear variables [252]. Hence, nonlinear techniques, particularly Kernel methods, are more powerful in terms of prediction accuracy and discrimination and are therefore naturally suitable for classification of volatomics data into, for instance, cancer and non-cancer categories [266,267]. More recently, ANNs are becoming popular in medical diagnosis [264]. ANNs is a fast, robust and highly predictive approach, involving powerful and flexible methods (it is a Euclidean metric based system that can handle complex data space) to model nonlinear problems. Although the interpretation of the effects of a compound is complicated, variants of ANNs have been applied in the analysis of sensor array results, MS data, and IMS measurements, among others [252]. An independent study using chemical sensors, for instance, has shown that ANNs is a preferred algorithm over other pattern recognition methods. This comparison was based on qualitative criteria (like speed, robustness of outlier, training difficulty, memory requirement and ability to produce measure of uncertainty), as well as quantitative criteria (classification accuracy) [268].

As already described, most EB studies involve a small sample size and a large number of variables. As a consequence, the statistical models developed can often suffer from overlearning or data overfitting $[251,269,270]$. Hence, a proper validation step is mandatory to increase the quality and robustness of the results. Ideally, this should include both a cross-validation as well as an external validation. Accordingly, in the cross-validation the datasets are randomly divided into " $n$ " subsets of equal size. The model is trained using (n-1) subsets and tested using the remaining subset, followed by the calculation of performance measures, such as accuracy, true and false positives, etc. The training and testing is repeated till all the subsets are used as test sets. The same performance measures (sensitivity, specificity and accuracy) are then calculated as average values of all the " $n$ " tests. It is also possible to use the "leave one out cross-validation" (LOO), where " $n$ " is equal to the data size. The following external validation should be performed with a totally new dataset obtained from unchallenged samples (also designated as blind samples) data which is equivalent to repetition of the experiments (using a similar sample size) on independent samples obtained from the originally tested population [270]. This strict and rigorous validation protocol is particularly pertinent when using data obtained using e-noses research [250]. In summary, the choice of the best data mining procedure involves most often an option between interpretation and accuracy because more robust data mining methods involve simultaneously a harder interpretation. Moreover, it is crucial build models using an analysis of large number of the 
samples. This, however, is often not possible, constituting a serious limitation to the discovery of robust biomarkers [270]. This is particularly true for EB VOCs suggested as diseases biomarkers. Invariably, as can be seen from Table 1, there are many EB VOCs that are described as potential biomarkers for different diseases, but they failed when applied in a typical clinical setup. To address this problem, it is desirable to have a standard protocol of guidelines for evaluating an EB analysis study. Such protocol/guidelines have been laid down as STARD guidelines for validating diagnostic tests [271]. These comprise a list of criteria to be used when evaluating a study that proposes a biomarker, before it is used for clinical application [272,273]. The main goal of this initiative is improve the analytical performance that is important for the characterisation of a disease biomarker, namely the necessary sensitivity to indicate the exclusion of a disease and specificity to distinguish between diseases. Additionally, processing of EB analysis data should be more consistent and include not only the analytical performance results (sensitivity, specificity, or provide receiver operator characteristic (ROC) curves with associated confidence intervals), as well as information about the statistical models used [270]. This is crucial for the replication of the results by other researchers and establishment of the best methodological tools for the characterisation of EB biomarkers. Another issue that would strength the utility of EB research in disease diagnose is the improvement of data fusion possibilities, developing tools to allow the merging of data obtained from different EB analysis approaches. Regarding this, Cunha et al. identified putative biomarkers for tuberculosis exploiting a data collection system that uses a differential mobility spectrometer (DMS) in parallel with a MS. With this approach, they could use synergistically the statistical tools previously developed for DMS in MS chemical identification [274]. Nevertheless, more research is required to allow merger of data obtained using the state of art approaches (GC-MS and PTR-MS, for instance) with the more recent POC e-noses technologies. Furthermore, integration of EB data with other biomarkers along with patients information (blood and urinary markers, medical history, existence of risk factors for a given disease, as being smoker and lung cancer, etc.) will perhaps pave way for a major breakthrough towards finding clinically usable non-invasive early disease diagnose.

\section{Conclusions}

Breath analysis is still in its infancy even though EB as a means to investigate VOCs was reported some forty years ago by Pauling et al. [18]. Nevertheless, many improvements have been made since that time, namely at the methodological point of view with the utilization of PTR-TOF-MS, as well as a plethora of sensing system and devices. The lacking of standardized sampling collection and data processing methodologies continue to constitute serious bottlenecks. Thus, a common EB analysis and data processing standard for the data generated from different platforms (GC-MS, PTR-MS, sensors, etc.) and storage of such data in databases as the Human Metabolome Database [275] and CanSAR [276], is a promising strategy to increase our understanding of human metabolism in health and disease and will certainly become an important trend very shortly. At another level, traditional VOCs data analysis is still quite cumbersome and time-consuming, requiring highly skilled personnel [23]. The variety of data mining resources available nowadays is also very large and difficult to understand. Therefore, further refinement of sampling techniques, exploring advanced statistical techniques on the multi-data of VOCs to build diagnostic and prognostic models and the search for new tools that combine the strengths of the eNose (cheap, time efficient), IMS (real-time), and GC-MS (sensitive and comprehensive, allowing 
compounds identification) would facilitate the introduction of VOCs analysis into clinical practice [23] through POC devices. In our view, breath analysis should be integrated with the current diagnostic tools to the early disease diagnosis very efficient.

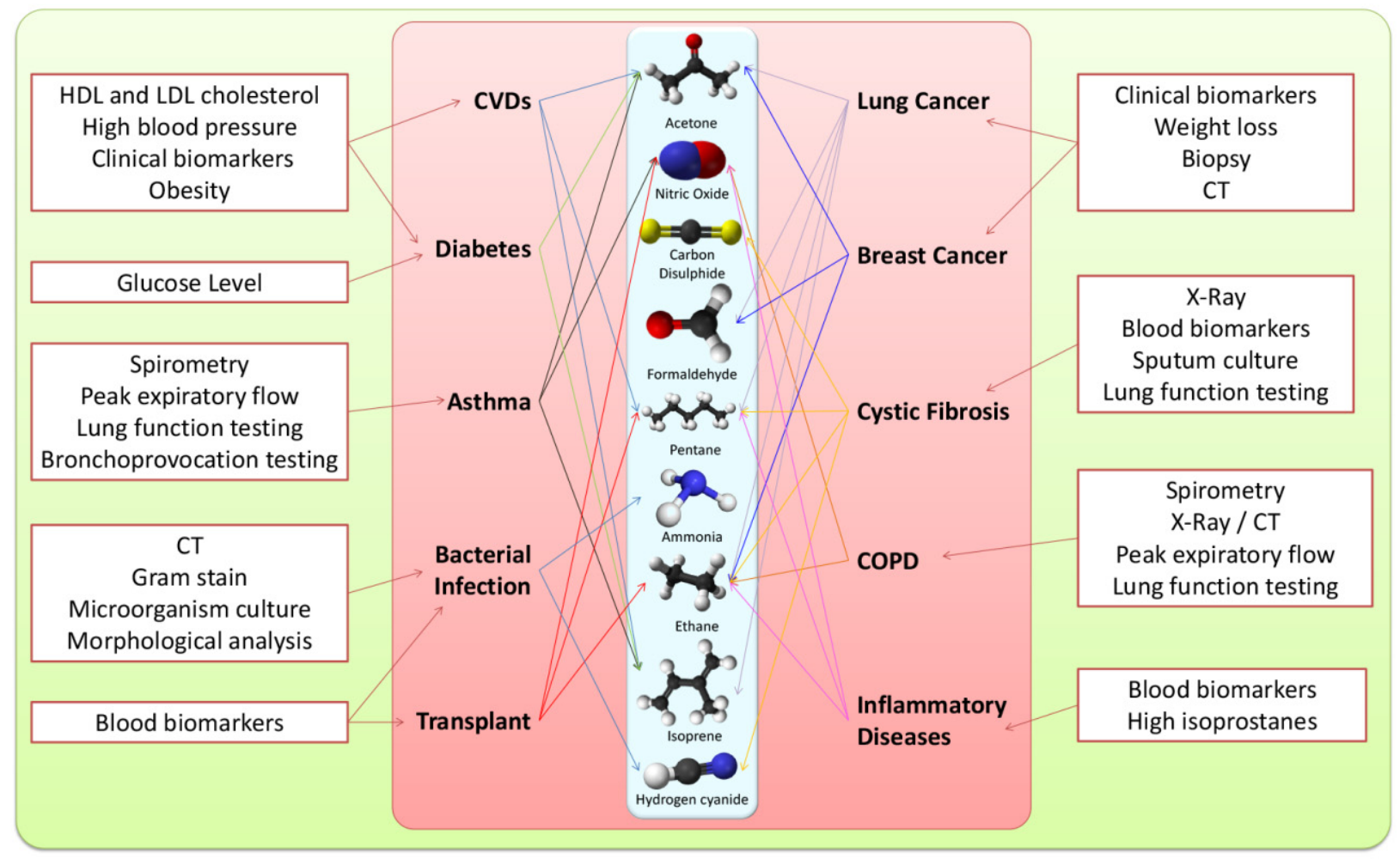

Figure 5. Workflow integrating breath analysis data with current diagnostic parameters to accelerate disease diagnose.

At another level, POC devices are mandatory for the use of EB analysis in the clinical environment. Unfortunately, most of the devices available are still prototypes and they are very far from coping with the complexity of EB analysis and substituting GC-MS and PTR-TOF-MS. Powerful bio-based sensor systems integrating cellular sensors and chip technology [277] and biological and chemical sensors based on graphene materials [278] are the new POC devices that would become available soon for clinical environment.

\section{Acknowledgments}

The authors acknowledge the Portuguese Foundation for Science and Technology (FCT) through the MS Portuguese Networks (REDE/1508/RNEM/2010), pluriannual base funding (Project PEst-OE/QUI/UI0674/2011), New-INDIGO/0003/2012 project (ERA- NET, FP 7) and BPD 66177/2009 given to JP. SR, KT, RD and HN gratefully acknowledge the support of Department of Biotechnology (DBT), Ministry of Science \& Technology, Government of India (New Indigo project BT/IN/New Indigo/03/RS/2013). 


\section{Author Contributions}

Jorge Pereira and José S. Câmara were responsible for designing the outline of the paper and critical review all manuscript before submission, Jorge Pereira was also responsible for Sections 1, 2 and 5, and for integrating all the different sections of the review. Priscilla Porto-Figueira and Carina Cavaco were responsible for the research for Section 2, Khushman Taunk and Srikanth Rapole were responsible for Section 3 and Rahul Dhakne and Hampapathalu were responsible for Section 4. Figure 1 was made by Jorge Pereira, Figure 2 by Priscilla Porto-Figueira, Figure 3 by Khushman Taunk, Srikanth Rapole and Priscilla Porto-Figueira and Figure 4 was made by Jorge Pereira and Priscilla Porto-Figueira. Table 1 was made with contributions of all authors.

\section{Abbreviations}

ACN-acetonitrile, ADH-Alcohol dehydrogenase, ADHF-Acute decompensated heart failure, AIDS-acquired immunodeficiency syndrome, AH-Alcoholic hepatitis, ALDH-aldehyde dehydrogenase, ANNs - artificial neural networks, TD-Thermal desorption, ATP-Adenosine triphosphate, AUC - area under the curves, BADD - breath analysis based disease diagnosis, $\mathrm{CAR}$ - Carboxen, $\mathrm{CF}$ - cystic fibrosis, $\mathrm{CKD}$ - chronic kidney disease, $\mathrm{CO}$ - carbon monoxide, $\mathrm{CO}_{2}$ - carbon dioxide, COPD — Chronic Obstructive Pulmonary Disease, CRC — colorectal cancer, CTcomputed tomography, CVDs - Cardiovascular diseases, DMPP-dimethylallyl pyrophosphate, DMA — Dimethyl amine, DNA — Deoxyribonucleic acid, DVB - Divinylbenzene, EB — exhaled breath, EBC - exhaled breath condensate, EDRF — endothelium-derived relaxing factor, EESI-MS - Extractive ElectroSpray Ionization Mass Spectrometry, FDH—formaldehyde dehydrogenase, FENO-NO fractional concentration in exhaled breath, FID_Flame ionization detector, HS-SPME-head-space solid phase micro extraction, FQDM—Fisher's Quadratic Discriminant Method, GC—gas chromatography, GC-FID — gas chromatography combined with Flame ionization detector, GC-IMS — gas chromatography combined with ion mobility spectrometer, GC-MS - gas chromatography combined with mass spectrometry, GC-TOF-MS — gas chromatography combined with time-of-flight mass spectrometry, GSH - glutathione, HCA-hierarchical clustering analysis, HF-Heart Failure, HMG-CoA reductase-3-hydroxy-3methyl-glutaryl-CoA reductase, IBD - Inflammatory Bowel Disease, ICU_-Intensive care unit, IL-4interleukin-4, IMS - ion mobility spectrometry, iNOS - inducible NO synthase, k-NN-k-nearest neighbour, LC - Lung cancer, LDA-linear discriminate analysis, LDCT-low dose computed tomography, LOD — limit of detection, MCCV — Monte Carlo cross-validation, MDA — malondialdehyde, MEPS - microextraction by packed sorbent, MLR - Multiple Linear Regressions, MVA — multivariated analysis, MS - mass spectrometry, m/z — mass to-charge ratio, NAFLD — Non-Alcoholic Fatty Liver Disease, NDDs — neurodegenerative diseases, NIR — near infrared spectroscopy, NLST — National Lung Screening Trial, $\mathrm{N}_{2}$-nitrogen, NNK-4-(methylnitrosamino)-1-(3-pyridyl)-1-butanone, NO-nitric oxide, NSCLC-Non-Small Cell Lung Carcinoma, NTD-Needle Trap Device, $\mathrm{O}_{2}$-oxygen, ODs_-Oncologic diseases, ppm—parts per million, ppb—parts per billion, ppt—parts per trillion, PCA-Principal Component Analysis, PDMS-Polydimethylsiloxane, PFA-perfluoroalkoxy polymer, PLS_Partial least-square, PNN_Probabilistic neural network, POC-point of care, PTFE — polytetrafluoroethylene, PVDC — polyvinylidene chloride, PVF — polyvinyl fluoride, PTR — proton 
transfer reaction, PTR-MS - proton transfer reaction with mass spectrometry, PTR-TOF-MS - proton transfer reaction with time-of-flight mass spectrometry, ROC-Receiver operator characteristic, RNS — reactive nitrogen species, ROS - reactive oxygen species, SIFT-MS—Selected ion flow tube mass spectrometry, SIMCA — soft independent modelling of class analogy, SPME — solid phase micro extraction, SVM - support vector machine, S/N — signal-to-noise ratio, TD-tubes - thermal desorption tubes, TGF- $\beta$ - transforming growth factor, TMA - trimethyl amine, TNF - tumour necrosis factor, TOF-MS - proton transfer reaction with time-of-flight mass spectrometry, VOCs - volatile organic compounds, WDA — weighted digital analysis

\section{Conflicts of Interest}

The authors declare no conflict of interest.

\section{References}

1. Boutayeb, A.; Boutayeb, S. The burden of non communicable diseases in developing countries. Int. J. Equity Health 2005, doi:10.1186/1475-9276-4-2.

2. Hossain, P.; Kawar, B.; El Nahas, M. Obesity and diabetes in the developing world--a growing challenge. N. Engl. J. Med. 2007, 356, 213-215.

3. Krisher, S.; Riley, A.; Mehta, K. Designing breathalyser technology for the developing world: How a single breath can fight the double disease burden. J. Med. Eng. Technol. 2014, 38, 156-163.

4. Silva, C.; Cavaco, C.; Perestrelo, R.; Pereira, J.; Câmara, J. Microextraction by packed sorbent (meps) and solid-phase microextraction (spme) as sample preparation procedures for the metabolomic profiling of urine. Metabolites 2014, 4, 71-97.

5. Morisco, F.; Aprea, E.; Lembo, V.; Fogliano, V.; Vitaglione, P.; Mazzone, G.; Cappellin, L.; Gasperi, F.; Masone, S.; De Palma, G.D.; Marmo, R.; Caporaso, N.; Biasioli, F. Rapid "breathprint" of liver cirrhosis by proton transfer reaction time-of-flight mass spectrometry. A pilot study. PLoS One 2013, 8, e59658.

6. Arasaradnam, R.P.; Covington, J.A.; Harmston, C.; Nwokolo, C.U. Review article: Next generation diagnostic modalities in gastroenterology--gas phase volatile compound biomarker detection. Aliment. Pharmacol. Ther. 2014, 39, 780-789.

7. Fens, N.; van der Schee, M.P.; Brinkman, P.; Sterk, P.J. Exhaled breath analysis by electronic nose in airways disease. Established issues and key questions. Clin. Exp. Allergy 2013, 43, 705-715.

8. Patel, K. Noninvasive tools to assess liver disease. Curr. Opin. Gastroenterol. 2010, 26, 227-233.

9. Probert, C.S.; Ahmed, I.; Khalid, T.; Johnson, E.; Smith, S.; Ratcliffe, N. Volatile organic compounds as diagnostic biomarkers in gastrointestinal and liver diseases. J. Gastrointestin. Liver Dis. 2009, 18, 337-343.

10. Phillips, M.; Herrera, J.; Krishnan, S.; Zain, M.; Greenberg, J.; Cataneo, R.N. Variation in volatile organic compounds in the breath of normal humans. J. Chromatogr. B 1999, 729, 75-88.

11. Schubert, J.; Miekisch, W.; Geiger, K.; Nöldge-Schomburg, G. Breath analysis in critically ill patients: Potential and limitations. Expert Rev. Mol. Diagn. 2004, 4, 619-629.

12. Bushdid, C.; Magnasco, M.O.; Vosshall, L.B.; Keller, A. Humans can discriminate more than 1 trillion olfactory stimuli. Science 2014, 343, 1370-1372. 
13. Risby, T.H.; Solga, S.F. Current status of clinical breath analysis. Appl. Phys. B 2006, 85, 421-426.

14. Kim, K.H.; Jahan, S.A.; Kabir, E. A review of breath analysis for diagnosis of human health. $\operatorname{Tr} A C$, Trends Anal. Chem. 2012, 33, 1-8.

15. Tittel, F.K. Current status of midinfrared quantum and interband cascade lasers for clinical breath analysis. Opt. Eng. 2010, 49, 111123.

16. Hakim, M.; Broza, Y.Y.; Barash, O.; Peled, N.; Phillips, M.; Amann, A.; Haick, H. Volatile organic compounds of lung cancer and possible biochemical pathways. Chem. Rev. 2012, 112, 5949-5966.

17. Minh Tdo, C.; Blake, D.R.; Galassetti, P.R. The clinical potential of exhaled breath analysis for diabetes mellitus. Diabetes Res. Clin. Pract. 2012, 97, 195-205.

18. Pauling, L.; Robinson, A.B.; Teranishi, R.; Cary, P. Quantitative analysis of urine vapor and breath by gas-liquid partition chromatography. Proc. Natl. Acad. Sci. USA 1971, 68, 2374-2376.

19. Gordon, S.M.; Szidon, J.P.; Krotoszynski, B.K.; Gibbons, R.D.; O'Neill, H.J. Volatile organic compounds in exhaled air from patients with lung cancer. Clin. Chem. 1985, 31, 1278-1282.

20. O'Neill, H.J.; Gordon, S.M.; O'Neill, M.H.; Gibbons, R.D.; Szidon, J.P. A computerized classification technique for screening for the presence of breath biomarkers in lung cancer. Clin. Chem. 1988, 34, 1613-1618.

21. Fenske, J.D.; Paulson, S.E. Human breath emissions of vocs. J. Air Waste Manag. Assoc. 1999, 49, 594-598.

22. Leja, M.A.; Liu, H.; Haick, H. Breath testing: The future for digestive cancer detection. Expert Rev. Gastroenterol. Hepatol. 2013, 7, 389-391.

23. van de Kant, K.D.; van der Sande, L.J.; Jobsis, Q.; van Schayck, O.C.; Dompeling, E. Clinical use of exhaled volatile organic compounds in pulmonary diseases: A systematic review. Respir. Res. 2012, 13, 117.

24. Amann, A.; Miekisch, W.; Pleil, J.; Risby, T.; Schubert, J. Methodological issues of sample collection and analysis of exhaled breath. In Methodological issues for breath analysis, Maney Publishing: Leeds, UK, 2010; Volume 49, pp. 96-114.

25. Amann, A.; Poupart, G.; Telser, S.; Ledochowski, M.; Schmid, A.; Mechtcheriakov, S. Applications of breath gas analysis in medicine. Int. J. Mass Spectrom. 2004, 239, 227-233.

26. Libardoni, M.; Stevens, P.T.; Waite, J.H.; Sacks, R. Analysis of human breath samples with a multi-bed sorption trap and comprehensive two-dimensional gas chromatography (gcxgc). J. Chromatogr. B 2006, 842, 13-21.

27. Altomare, D.F.; Di Lena, M.; Porcelli, F.; Trizio, L.; Travaglio, E.; Tutino, M.; Dragonieri, S.; Memeo, V.; de Gennaro, G. Exhaled volatile organic compounds identify patients with colorectal cancer. Br. J. Surg. 2013, 100, 144-150.

28. Samara, M.A.; Tang, W.H.; Cikach, F., Jr.; Gul, Z.; Tranchito, L.; Paschke, K.M.; Viterna, J.; Wu, Y.; Laskowski, D.; Dweik, R.A. Single exhaled breath metabolomic analysis identifies unique breathprint in patients with acute decompensated heart failure. J. Am. Coll. Cardiol. 2013, 61, 1463-1464.

29. Cikach, F.S., Jr.; Dweik, R.A. Cardiovascular biomarkers in exhaled breath. Prog. Cardiovasc. Dis. 2012, 55, 34-43. 
30. Bajtarevic, A.; Ager, C.; Pienz, M.; Klieber, M.; Schwarz, K.; Ligor, M.; Ligor, T.; Filipiak, W.; Denz, H.; Fiegl, M., et al. Noninvasive detection of lung cancer by analysis of exhaled breath. BMC Cancer 2009, 9, 348.

31. Haick, H.; Broza, Y.Y.; Mochalski, P.; Ruzsanyi, V.; Amann, A. Assessment, origin, and implementation of breath volatile cancer markers. Chem. Soc. Rev. 2014, 43, 1423-1449.

32. Pleil, J.D.; Lindstrom, A.B. Collection of a single alveolar exhaled breath for volatile organic compounds analysis. Am. J. Ind. Med. 1995, 28, 109-121.

33. Schubert, J.K.; Miekisch, W. Chapter 9 - breath analysis in critically ill patients-potential and limitations. In Volatile biomarkers, Amann, A.; Smith, D., Eds. Elsevier: Boston, 2013; pp. 155-176.

34. Miekisch, W.; Schubert, J. From highly sophisticated analytical techniques to life-saving diagnostics: Technical developments in breath analysis. TrAC, Trends Anal. Chem. 2006, 25, 665-673.

35. Miekisch, W.; Kischkel, S.; Sawacki, A.; Liebau, T.; Mieth, M.; Schubert, J.K. Impact of sampling procedures on the results of breath analysis. J. Breath Res. 2008, 2, 026007.

36. Buszewski, B.; Kesy, M.; Ligor, T.; Amann, A. Human exhaled air analytics: Biomarkers of diseases. Biomed. Chromatogr. 2007, 21, 553-566.

37. Beauchamp, J.; Herbig, J.; Gutmann, R.; Hansel, A. On the use of tedlar(r) bags for breath-gas sampling and analysis. J. Breath Res. 2008, 2, 046001.

38. Birgitta, S.; Fredrik, W.; Anders, V. Analysis of breath samples for lung cancer survival. Anal. Chim. Acta 2014, 840, 82-86.

39. Fu, X.A.; Li, M.; Knipp, R.J.; Nantz, M.H.; Bousamra, M. Noninvasive detection of lung cancer using exhaled breath. Cancer Med. 2014, 3, 174-181.

40. Trabue, S.L.; Anhalt, J.C.; Zahn, J.A. Bias of tedlar bags in the measurement of agricultural odorants names are necessary to report factually on available data; however, the usda neither guarantees nor warrants the standard of the product, and use of the name by the usda implies no approval of the product to the exclusion of others that may be suitable. J. Environ. Qual. 2006, 35, $1668-1677$.

41. Mieth, M.; Kischkel, S.; Schubert, J.K.; Hein, D.; Miekisch, W. Multibed needle trap devices for on site sampling and preconcentration of volatile breath biomarkers. Anal. Chem. 2009, 81, 5851-5857.

42. Hyšpler, R.R.; Crhová, Š.; Gasparič, J.; Zadák, Z.; Č́žžková, M.; Balasová, V. Determination of isoprene in human expired breath using solid-phase microextraction and gas chromatography — mass spectrometry. J. Chromatogr. B 2000, 739, 183-190.

43. Grabowska-Polanowska, B.; Faber, J.; Skowron, M.; Miarka, P.; Pietrzycka, A.; Sliwka, I.; Amann, A. Detection of potential chronic kidney disease markers in breath using gas chromatography with mass-spectral detection coupled with thermal desorption method. J. Chromatogr. A 2013, 1301, 179-189.

44. Szulejko, J.E.; Kim, K.-H. A review of sampling and pretreatment techniques for the collection of airborne amines. TrAC, Trends Anal. Chem. 2014, 57, 118-134.

45. Wang, C.; Ke, C.; Wang, X.; Chi, C.; Guo, L.; Luo, S.; Guo, Z.; Xu, G.; Zhang, F.; Li, E. Noninvasive detection of colorectal cancer by analysis of exhaled breath. Anal. Bioanal. Chem. 2014, 406, 4757-4763. 
46. Mutlu, G.M.; Garey, K.W.; Robbins, R.A.; Danziger, L.H.; Rubinstein, I. Collection and analysis of exhaled breath condensate in humans. Am. J. Respir. Crit. Care. Med. 2001, 164, 731-737.

47. Ahmadzai, H.; Huang, S.; Hettiarachchi, R.; Lin, J.L.; Thomas, P.S.; Zhang, Q. Exhaled breath condensate: A comprehensive update. Clin. Chem. Lab. Med. 2013, 51, 1343-1361.

48. Kuban, P.; Foret, F. Exhaled breath condensate: Determination of non-volatile compounds and their potential for clinical diagnosis and monitoring. A review. Anal. Chim. Acta 2013, 805, 1-18.

49. Rosias, P. Methodological aspects of exhaled breath condensate collection and analysis. J. Breath Res. 2012, 6, 027102.

50. Soyer, O.U.; Dizdar, E.A.; Keskin, O.; Lilly, C.; Kalayci, O. Comparison of two methods for exhaled breath condensate collection. Allergy 2006, 61, 1016-1018.

51. Huttmann, E.M.; Greulich, T.; Hattesohl, A.; Schmid, S.; Noeske, S.; Herr, C.; John, G.; Jorres, R.A.; Muller, B.; Vogelmeier, C. et al. Comparison of two devices and two breathing patterns for exhaled breath condensate sampling. PLoS One 2011, 6, e27467.

52. Woolfenden, E. Sorbent-based sampling methods for volatile and semi-volatile organic compounds in air. Part 2. Sorbent selection and other aspects of optimizing air monitoring methods. J. Chromatogr. A 2010, 1217, 2685-2694.

53. Woolfenden, E. Sorbent-based sampling methods for volatile and semi-volatile organic compounds in air part 1: Sorbent-based air monitoring options. J. Chromatogr. A 2010, 1217, 2674-2684.

54. Trimble, T.A.; You, J.; Lydy, M.J. Bioavailability of pcbs from field-collected sediments: Application of tenax extraction and matrix-spme techniques. Chemosphere 2008, 71, 337-344.

55. Garrido-Delgado, R.; Mercader-Trejo, F.; Arce, L.; Valcarcel, M. Enhancing sensitivity and selectivity in the determination of aldehydes in olive oil by use of a tenax ta trap coupled to a uv-ion mobility spectrometer. J. Chromatogr. A 2011, 1218, 7543-7549.

56. Reynolds, J.C.; Jimoh, M.A.; Guallar-Hoyas, C.; Creaser, C.S.; Siddiqui, S.; Paul Thomas, C.L. Analysis of human breath samples using a modified thermal desorption: Gas chromatography electrospray ionization interface. J. Breath Res. 2014, 8, 037105.

57. Reynolds, J.C.; Blackburn, G.J.; Guallar-Hoyas, C.; Moll, V.H.; Bocos-Bintintan, V.; Kaur-Atwal, G.; Howdle, M.D.; Harry, E.L.; Brown, L.J.; Creaser, C.S., et al. Detection of volatile organic compounds in breath using thermal desorption electrospray ionization-ion mobility-mass spectrometry. Anal. Chem. 2010, 82, 2139-2144.

58. Wzorek, B.; Mochalski, P.; Sliwka, I.; Amann, A. Application of gc-ms with a spme and thermal desorption technique for determination of dimethylamine and trimethylamine in gaseous samples for medical diagnostic purposes. J. Breath Res. 2010, doi:10.1088/1752-7155/4/2/026002.

59. van der Schee, M.P.; Fens, N.; Brinkman, P.; Bos, L.D.; Angelo, M.D.; Nijsen, T.M.; Raabe, R.; Knobel, H.H.; Vink, T.J.; Sterk, P.J. Effect of transportation and storage using sorbent tubes of exhaled breath samples on diagnostic accuracy of electronic nose analysis. J. Breath Res. 2013, doi:10.1088/1752-7155/7/1/016002.

60. Demeestere, K.; Dewulf, J.; De Witte, B.; Van Langenhove, H. Sample preparation for the analysis of volatile organic compounds in air and water matrices. J. Chromatogr. A 2007, 1153, 130-144.

61. Grote, C.; Pawliszyn, J. Solid-phase microextraction for the analysis of human breath. Anal. Chem. 1997, 69, 587-596. 
62. Pawliszyn, J. Applications of Solid Phase Microextraction; Royal Society of Chemistry: Cambridge, UK, 1999; Volume 5.

63. Pawliszyn, J.; Pawliszyn, B.; Pawliszyn, M. Solid phase microextraction (spme). Chem. Educ. 1997, 2, 1-7.

64. Risticevic, S.; Niri, V.H.; Vuckovic, D.; Pawliszyn, J. Recent developments in solid-phase microextraction. Anal. Bioanal. Chem. 2009, 393, 781-795.

65. Spietelun, A.; Pilarczyk, M.; Kloskowski, A.; Namiesnik, J. Current trends in solid-phase microextraction (spme) fibre coatings. Chem. Soc. Rev. 2010, 39, 4524-4537.

66. Pawliszyn, J.; Pedersen-Bjergaard, S. Analytical microextraction: Current status and future trends. J. Chromatogr. Sci. 2006, 44, 291-307.

67. Pereira, J.; Silva, C.L.; Perestrelo, R.; Goncalves, J.; Alves, V.; Camara, J.S. Re-exploring the high-throughput potential of microextraction techniques, spme and meps, as powerful strategies for medical diagnostic purposes. Innovative approaches, recent applications and future trends. Anal. Bioanal. Chem. 2014, 406, 2101-2122.

68. Vuckovic, D.; Zhang, X.; Cudjoe, E.; Pawliszyn, J. Solid-phase microextraction in bioanalysis: New devices and directions. J. Chromatogr. A 2010, 1217, 4041-4060.

69. Trefz, P.; Rösner, L.; Hein, D.; Schubert, J.; Miekisch, W. Evaluation of needle trap microextraction and automatic alveolar sampling for point-of-care breath analysis. Anal. Bioanal. Chem. 2013, 405, 3105-3115.

70. Lord, H.; Zhan, W.; Pawliszyn, J. Fundamentals and applications of needle trap devices: A critical review. Anal. Chim. Acta 2010, 677, 3-18.

71. Trefz, P.; Kischkel, S.; Hein, D.; James, E.; Schubert, J.; Miekisch, W. Needle trap micro-extraction for voc analysis: Effects of packing materials and desorption parameters. J. Chromatogr. A 2012, 1219, 29-38.

72. Mesarchaki, E.; Yassaa, N.; Hein, D.; Lutterbeck, H.E.; Zindler, C.; Williams, J. A novel method for the measurement of vocs in seawater using needle trap devices and gc-ms. Mar. Chem. 2014, 159, 1-8.

73. Smith, D.; Spaněl, P.; Herbig, J.; Beauchamp, J. Mass spectrometry for real-time quantitative breath analysis. J. Breath Res. 2014, 8, 27101.

74. Fink, T.; Baumbach, J.I.; Kreuer, S. Ion mobility spectrometry in breath research. J. Breath Res. 2014, 8, 027104.

75. Wang, C.; Sahay, P. Breath analysis using laser spectroscopic techniques: Breath biomarkers, spectral fingerprints, and detection limits. Sensors 2009, 9, 8230-8262.

76. Rock, F.; Barsan, N.; Weimar, U. Electronic nose: Current status and future trends. Chem. Rev. 2008, 108, 705-725.

77. Jansson, B.O.; Larsson, B.T. Analysis of organic compounds in human breath by gas chromatography-mass spectrometry. J. Lab. Clin. Med. 1969, 74, 961-966.

78. Chen, S.; Zieve, L.; Mahadevan, V. Mercaptans and dimethyl sulfide in the breath of patients with cirrhosis of the liver. Effect of feeding methionine. J. Lab. Clin. Med. 1970, 75, 628-635.

79. Riely, C.A.; Cohen, G.; Lieberman, M. Ethane evolution: A new index of lipid peroxidation. Science 1974, 183, 208-210. 
80. Dannecker, J.R., Jr.; Shaskan, E.G.; Phillips, M. A new highly sensitive assay for breath acetaldehyde: Detection of endogenous levels in humans. Anal. Biochem. 1981, 114, 1-7.

81. Cao, W.; Duan, Y. Current status of methods and techniques for breath analysis. Crit. Rev. Anal. Chem. 2007, 37, 3-13.

82. Peled, N.; Hakim, M.; Bunn, P.A., Jr.; Miller, Y.E.; Kennedy, T.C.; Mattei, J.; Mitchell, J.D.; Hirsch, F.R.; Haick, H. Non-invasive breath analysis of pulmonary nodules. J. Thorac. Oncol. 2012, 7, 1528-1533.

83. Poli, D.; Carbognani, P.; Corradi, M.; Goldoni, M.; Acampa, O.; Balbi, B.; Bianchi, L.; Rusca, M.; Mutti, A. Exhaled volatile organic compounds in patients with non-small cell lung cancer: Cross sectional and nested short-term follow-up study. Respir. Res. 2005, 6, doi:10.1186/14659921-6-71.

84. Wehinger, A.; Schmid, A.; Mechtcheriakov, S.; Ledochowski, M.; Grabmer, C.; Gastl, G.A.; Amann, A. Lung cancer detection by proton transfer reaction mass-spectrometric analysis of human breath gas. Int. J. Mass Spectrom. 2007, 265, 49-59.

85. Fuchs, P.; Loeseken, C.; Schubert, J.K.; Miekisch, W. Breath gas aldehydes as biomarkers of lung cancer. Int. J. Cancer 2010, 126, 2663-2670.

86. Paredi, P.; Kharitonov, S.A.; Barnes, P.J. Elevation of exhaled ethane concentration in asthma. Am. J. Respir. Crit. Care. Med. 2000, 162, 1450-1454.

87. Kischkel, S.; Miekisch, W.; Sawacki, A.; Straker, E.M.; Trefz, P.; Amann, A.; Schubert, J.K. Breath biomarkers for lung cancer detection and assessment of smoking related effects-confounding variables, influence of normalization and statistical algorithms. Clin. Chim. Acta 2010, 411, 1637-1644.

88. Di Natale, C.; Macagnano, A.; Martinelli, E.; Paolesse, R.; D'Arcangelo, G.; Roscioni, C.; FinazziAgrò, A.; D'Amico, A. Lung cancer identification by the analysis of breath by means of an array of non-selective gas sensors. Biosens. Bioelectron. 2003, 18, 1209-1218.

89. Chen, X.; Cao, M.; Li, Y.; Hu, W.; Wang, P.; Ying, K.; Pan, H. A study of an electronic nose for detection of lung cancer based on a virtual saw gas sensors array and imaging recognition method. Meas. Sci. Technol. 2005, 16, 1535-1546.

90. Machado, R.F.; Laskowski, D.; Deffenderfer, O.; Burch, T.; Zheng, S.; Mazzone, P.J.; Mekhail, T.; Jennings, C.; Stoller, J.K.; Pyle, J., et al. Detection of lung cancer by sensor array analyses of exhaled breath. Am. J. Respir. Crit. Care. Med. 2005, 171, 1286-1291.

91. Mazzone, P.J.; Hammel, J.; Dweik, R.; Na, J.; Czich, C.; Laskowski, D.; Mekhail, T. Diagnosis of lung cancer by the analysis of exhaled breath with a colorimetric sensor array. Thorax 2007, 62, 565-568.

92. Dragonieri, S.; Annema, J.T.; Schot, R.; van der Schee, M.P.C.; Spanevello, A.; Carratú, P.; Resta, O.; Rabe, K.F.; Sterk, P.J. An electronic nose in the discrimination of patients with non-small cell lung cancer and copd. Lung Cancer 2009, 64, 166-170.

93. Peng, G.; Tisch, U.; Adams, O.; Hakim, M.; Shehada, N.; Broza, Y.Y.; Billan, S.; Abdah-Bortnyak, R.; Kuten, A.; Haick, H. Diagnosing lung cancer in exhaled breath using gold nanoparticles. Nat. Nanotechnol. 2009, 4, 669-673. 
94. Mazzone, P.J.; Wang, X.F.; Xu, Y.; Mekhail, T.; Beukemann, M.C.; Na, J.; Kemling, J.W.; Suslick, K.S.; Sasidhar, M. Exhaled breath analysis with a colorimetric sensor array for the identification and characterization of lung cancer. J. Thorac. Oncol. 2012, 7, 137-142.

95. Broza, Y.Y.; Kremer, R.; Tisch, U.; Gevorkyan, A.; Shiban, A.; Best, L.A.; Haick, H. A nanomaterial-based breath test for short-term follow-up after lung tumor resection. Nanomed. 2013, 9, 15-21.

96. Chapman, E.A.; Thomas, P.S.; Stone, E.; Lewis, C.; Yates, D.H. A breath test for malignant mesothelioma using an electronic nose. Eur. Respir. J. 2012, 40, 448-454.

97. de Gennaro, G.; Dragonieri, S.; Longobardi, F.; Musti, M.; Stallone, G.; Trizio, L.; Tutino, M. Chemical characterization of exhaled breath to differentiate between patients with malignant plueral mesothelioma from subjects with similar professional asbestos exposure. Anal. Bioanal. Chem. 2010, 398, 3043-3050.

98. Dragonieri, S.; van der Schee, M.P.; Massaro, T.; Schiavulli, N.; Brinkman, P.; Pinca, A.; Carratú, P.; Spanevello, A.; Resta, O.; Musti, M., et al. An electronic nose distinguishes exhaled breath of patients with malignant pleural mesothelioma from controls. Lung Cancer 2012, 75, 326-331.

99. Phillips, M.; Cataneo, R.; Ditkoff, B.; Fisher, P.; Greenberg, J.; Gunawardena, R.; Kwon, C.; Rahbari-Oskoui, F.; Wong, C. Volatile markers of breast cancer in the breath. Breast J. 2003, 9, 184-191.

100. Phillips, M.; Cataneo, R.N.; Saunders, C.; Hope, P.; Schmitt, P.; Wai, J. Volatile biomarkers in the breath of women with breast cancer. J. Breath Res. 2010, 4, doi:10.1088/1752-7155/4/2/026003.

101. Peng, G.; Hakim, M.; Broza, Y.Y.; Billan, S.; Abdah-Bortnyak, R.; Kuten, A.; Tisch, U.; Haick, H. Detection of lung, breast, colorectal, and prostate cancers from exhaled breath using a single array of nanosensors. Br. J. Cancer 2010, 103, 542-551.

102. Li, J.; Peng, Y.; Liu, Y.; Li, W.; Jin, Y.; Tang, Z.; Duan, Y. Investigation of potential breath biomarkers for the early diagnosis of breast cancer using gas chromatography-mass spectrometry. Clin. Chim. Acta 2014, 436c, 59-67.

103. Phillips, M.; Beatty, J.D.; Cataneo, R.N.; Huston, J.; Kaplan, P.D.; Lalisang, R.I.; Lambin, P.; Lobbes, M.B.I.; Mundada, M.; Pappas, N., et al. Rapid point-of-care breath test for biomarkers of breast cancer and abnormal mammograms. PLoS One 2014, 9, doi:10.1371/journal.pone.0090226.

104. Shuster, G.; Gallimidi, Z.; Reiss, A.H.; Dovgolevsky, E.; Billan, S.; Abdah-Bortnyak, R.; Kuten, A.; Engel, A.; Shiban, A.; Tisch, U., et al. Classification of breast cancer precursors through exhaled breath. Breast Cancer Res. Treat. 2011, 126, 791-796.

105. Xu, Z.Q.; Broza, Y.Y.; Ionsecu, R.; Tisch, U.; Ding, L.; Liu, H.; Song, Q.; Pan, Y.Y.; Xiong, F.X.; $\mathrm{Gu}$, K.S., et al. A nanomaterial-based breath test for distinguishing gastric cancer from benign gastric conditions. Br. J. Cancer 2013, 108, 941-950.

106. Hakim, M.; Billan, S.; Tisch, U.; Peng, G.; Dvrokind, I.; Marom, O.; Abdah-Bortnyak, R.; Kuten, A.; Haick, H. Diagnosis of head-and-neck cancer from exhaled breath. Br. J. Cancer 2011, 104, 1649-1655.

107. Leunis, N.; Boumans, M.L.; Kremer, B.; Din, S.; Stobberingh, E.; Kessels, A.G.; Kross, K.W. Application of an electronic nose in the diagnosis of head and neck cancer. Laryngoscope 2014, 124, 1377-1381. 
108. Amal, H.; Ding, L.; Liu, B.B.; Tisch, U.; Xu, Z.Q.; Shi, D.Y.; Zhao, Y.; Chen, J.; Sun, R.X.; Liu, H., et al. The scent fingerprint of hepatocarcinoma: In-vitro metastasis prediction with volatile organic compounds (VOCs). Int. J. Nanomed. 2012, 7, 4135-4146.

109. Xue, R.; Dong, L.; Zhang, S.; Deng, C.; Liu, T.; Wang, J.; Shen, X. Investigation of volatile biomarkers in liver cancer blood using solid-phase microextraction and gas chromatography/mass spectrometry. Rapid Commun. Mass Spectrom. 2008, 22, 1181-1186.

110. Qin, T.; Liu, H.; Song, Q.; Song, G.; Wang, H.Z.; Pan, Y.Y.; Xiong, F.X.; Gu, K.S.; Sun, G.P.; Chen, Z.D. The screening of volatile markers for hepatocellular carcinoma. Cancer Epidemiol. Biomarkers Prev. 2010, 19, 2247-2253.

111. Guo, D.; Zhang, D.; Li, N.; Zhang, L.; Yang, J. A novel breath analysis system based on electronic olfaction. IEEE Trans. Bio-Med. Eng. 2010, doi:10.1109/TBME.2010.2055864.

112. Dragonieri, S.; Schot, R.; Mertens, B.J.A.; Le Cessie, S.; Gauw, S.A.; Spanevello, A.; Resta, O.; Willard, N.P.; Vink, T.J.; Rabe, K.F., et al. An electronic nose in the discrimination of patients with asthma and controls. J. Allergy Clin. Immunol. 2007, 120, 856-862.

113. Caldeira, M.; Barros, A.S.; Bilelo, M.J.; Parada, A.; Câmara, J.S.; Rocha, S.M. Profiling allergic asthma volatile metabolic patterns using a headspace-solid phase microextraction/gas chromatography based methodology. J. Chromatogr. A 2011, 1218, 3771-3780.

114. Caldeira, M.; Perestrelo, R.; Barros, A.S.; Bilelo, M.J.; Morête, A.; Câmara, J.S.; Rocha, S.M. Allergic asthma exhaled breath metabolome: A challenge for comprehensive two-dimensional gas chromatography. J. Chromatogr. A 2012, 1254, 87-97.

115. Dallinga, J.W.; Robroeks, C.M.H.H.T.; Van Berkel, J.J.B.N.; Moonen, E.J.C.; Godschalk, R.W.L.; Jöbsis, Q.; Dompeling, E.; Wouters, E.F.M.; Van Schooten, F.J. Volatile organic compounds in exhaled breath as a diagnostic tool for asthma in children. Clin. Exp. Allergy 2010, 40, 68-76.

116. Montuschi, P.; Santonico, M.; Mondino, C.; Pennazza, G.; Mantini, G.; Martinelli, E.; Capuano, R.; Ciabattoni, G.; Paolesse, R.; Di Natale, C., et al. Diagnostic performance of an electronic nose, fractional exhaled nitric oxide, and lung function testing in asthma. Chest 2010, 137, 790-796.

117. Smolinska, A.; Klaassen, E.M.M.; Dallinga, J.W.; van de Kant, K.D.G.; Jobsis, Q.; Moonen, E.J.C.; van Schayck, O.C.P.; Dompeling, E.; van Schooten, F.J. Profiling of volatile organic compounds in exhaled breath as a strategy to find early predictive signatures of asthma in children. PLoS One 2014, 9, doi:10.1371/journal.pone.0095668.

118. Bos, L.D.; Weda, H.; Wang, Y.; Knobel, H.H.; Nijsen, T.M.; Vink, T.J.; Zwinderman, A.H.; Sterk, P.J.; Schultz, M.J. Exhaled breath metabolomics as a noninvasive diagnostic tool for acute respiratory distress syndrome. Eur. Respir. J. 2014.

119. Schubert, J.K.; Müller, W.P.; Benzing, A.; Geiger, K. Application of a new method for analysis of exhaled gas in critically ill patients. Intensiv. Care Med. 1998, 24, 415-421.

120. Fens, N.; Douma, R.A.; Sterk, P.J.; Kamphuisen, P.W. Breathomics as a diagnostic tool for pulmonary embolism. J. Thromb. Haemost. 2010, 8, 2831-2833.

121. Phillips, M.; Cataneo, R.N.; Condos, R.; Ring Erickson, G.A.; Greenberg, J.; La Bombardi, V.; Munawar, M.I.; Tietje, O. Volatile biomarkers of pulmonary tuberculosis in the breath. Tuberculosis 2007, 87, 44-52. 
122. Phillips, M.; Basa-Dalay, V.; Bothamley, G.; Cataneo, R.N.; Lam, P.K.; Natividad, M.P.; Schmitt, P.; Wai, J. Breath biomarkers of active pulmonary tuberculosis. Tuberculosis (Edinb.) 2010, 90, 145-151.

123. Phillips, M.; Basa-Dalay, V.; Blais, J.; Bothamley, G.; Chaturvedi, A.; Modi, K.D.; Pandya, M.; Natividad, M.P.; Patel, U.; Ramraje, N.N., et al. Point-of-care breath test for biomarkers of active pulmonary tuberculosis. Tuberculosis (Edinb.) 2012, 92, 314-320.

124. Paredi, P.; Kharitonov, S.A.; Leak, D.; Ward, S.; Cramer, D.; Barnes, P.J. Exhaled ethane, a marker of lipid peroxidation, is elevated in chronic obstructive pulmonary disease. Am. J. Respir. Crit. Care. Med. 2000, 162, 369-373.

125. Corradi, M.; Rubinstein, I.; Andreoli, R.; Manini, P.; Caglieri, A.; Poli, D.; Alinovi, R.; Mutti, A. Aldehydes in exhaled breath condensate of patients with chronic obstructive pulmonary disease. Am. J. Respir. Crit. Care. Med. 2003, 167, 1380-1386.

126. Cristescu, S.M.; Gietema, H.A.; Blanchet, L.; Kruitwagen, C.L.; Munnik, P.; van Klaveren, R.J.; Lammers, J.W.; Buydens, L.; Harren, F.J.; Zanen, P. Screening for emphysema via exhaled volatile organic compounds. J. Breath Res.2011, 5, doi:10.1088/1752-7155/5/4/046009.

127. Hattesohl, A.D.M.; Jörres, R.a.; Dressel, H.; Schmid, S.; Vogelmeier, C.; Greulich, T.; Noeske, S.; Bals, R.; Koczulla, A.R. Discrimination between copd patients with and without alpha 1-antitrypsin deficiency using an electronic nose. Respirology (Carlton, Vic.) 2011, 16, 1258-1264.

128. Hauschild, A.C.; Baumbach, J.I.; Baumbach, J. Integrated statistical learning of metabolic ion mobility spectrometry profiles for pulmonary disease identification. Genet. Mol. Res. 2012, 11, 2733-2744.

129. Barker, M.; Hengst, M.; Schmid, J.; Buers, H.J.; Mittermaier, B.; Klemp, D.; Koppmann, R. Volatile organic compounds in the exhaled breath of young patients with cystic fibrosis. Eur. Respir. J. 2006, 27, 929-936.

130. Kamboures, M.A.; Blake, D.R.; Cooper, D.M.; Newcomb, R.L.; Barker, M.; Larson, J.K.; Meinardi, S.; Nussbaum, E.; Rowland, F.S. Breath sulfides and pulmonary function in cystic fibrosis. Proc. Natl. Acad. Sci. USA 2005, 102, 15762-15767.

131. Paredi, P.; Kharitonov, S.A.; Leak, D.; Shah, P.L.; Cramer, D.; Hodson, M.E.; Barnes, P.J. Exhaled ethane is elevated in cystic fibrosis and correlates with carbon monoxide levels and airway obstruction. Am. J. Respir. Crit. Care. Med. 2000, 161, 1247-1251.

132. Marcondes-Braga, F.G.; Gutz, I.G.; Batista, G.L.; Saldiva, P.H.; Ayub-Ferreira, S.M.; Issa, V.S.; Mangini, S.; Bocchi, E.A.; Bacal, F. Exhaled acetone as a new biomaker of heart failure severity. Chest 2012, 142, 457-466.

133. Zhan, X.; Duan, J.; Duan, Y. Recent developments of proton-transfer reaction mass spectrometry (PTR-MS) and its applications in medical research. Mass Spectrom. Rev. 2013, 32, 143-165.

134. Alkhouri, N.; Cikach, F.; Eng, K.; Moses, J.; Patel, N.; Yan, C.; Hanouneh, I.; Grove, D.; Lopez, R.; Dweik, R. Analysis of breath volatile organic compounds as a noninvasive tool to diagnose nonalcoholic fatty liver disease in children. Eur. J. Gastroenterol. Hepatol. 2014, 26, 82-87.

135. Hanouneh, I.A.; Zein, N.N.; Cikach, F.; Dababneh, L.; Grove, D.; Alkhouri, N.; Lopez, R.; Dweik, R.A. The breathprints in patients with liver disease identify novel breath biomarkers in alcoholic hepatitis. Clin. Gastroenterol. Hepatol. 2014, 12, 516-523. 
136. Walton, C.; Patel, M.; Pitts, D.; Knight, P.; Hoashi, S.; Evans, M.; Turner, C. The use of a portable breath analysis device in monitoring type 1 diabetes patients in a hypoglycaemic clamp: Validation with sift-ms data. J. Breath Res. 2014, doi:10.1088/1752-7155/8/3/037108.

137. Storer, M.; Dummer, J.; Lunt, H.; Scotter, J.; McCartin, F.; Cook, J.; Swanney, M.; Kendall, D.; Logan, F.; Epton, M. Measurement of breath acetone concentrations by selected ion flow tube mass spectrometry in type 2 diabetes. J. Breath Res. 2011, 5, 046011.

138. Yan, Y.; Wang, Q.; Li, W.; Zhao, Z.; Yuan, X.; Huang, Y.; Duan, Y. Discovery of potential biomarkers in exhaled breath for diagnosis of type 2 diabetes mellitus based on gc-ms with metabolomics. RSC Advances 2014, 4, 25430.

139. Matsumoto, A.; Hirata, Y.; Kakoki, M.; Nagata, D.; Momomura, S.; Sugimoto, T.; Tagawa, H.; Omata, M. Increased excretion of nitric oxide in exhaled air of patients with chronic renal failure. Clin. Sci. 1999, 96, 67-74.

140. Pagonas, N.; Vautz, W.; Seifert, L.; Slodzinski, R.; Jankowski, J.; Zidek, W.; Westhoff, T.H. Volatile organic compounds in uremia. PLoS One 2012, 7, doi:10.1371/journal.pone.0046258.

141. Bodelier A; Smolinska A; Dallinga J; Masclee A, Jonkers D, Pierik M, van Schooten F-J. Volatile organic compound in breath as a new test for crohn's disease activity. United Eur. Gastroenterol. J. 2013, 1, A36.

142. Crosson, E.R.; Ricci, K.N.; Richman, B.A.; Chilese, F.C.; Owano, T.G.; Provencal, R.A.; Todd, M.W.; Glasser, J.; Kachanov, A.A.; Paldus, B.A., et al. Stable isotope ratios using cavity ring-down spectroscopy: Determination of $13 \mathrm{c} / 12 \mathrm{c}$ for carbon dioxide in human breath. Anal. Chem. 2002, 74, 2003-2007.

143. Ross, B.M. Increased breath ethane and pentane concentrations in currently unmedicated patients with schizophrenia. Open J. Psychiatry 2011, 01, 1-7.

144. Herbig, J.; Muller, M.; Schallhart, S.; Titzmann, T.; Graus, M.; Hansel, A. On-line breath analysis with ptr-tof. J. Breath Res. 2009, doi:10.1088/1752-7155/3/2/027004.

145. Sethi, S.; Nanda, R.; Chakraborty, T. Clinical application of volatile organic compound analysis for detecting infectious diseases. Clin. Microbiol. Rev. 2013, 26, 462-475.

146. Phillip, T.; Markus, S.; Peter, O.; Juliane, O.; Beate, B.; Svend, K.; Jürgen, D.; Ralf, Z.; Jochen, K.S.; Wolfram, M. Continuous real time breath gas monitoring in the clinical environment by proton-transfer-reaction-time-of-flight-mass spectrometry. Anal. Chem. 2013, 85, 10321-10329.

147. McCurdy, M.R.; Bakhirkin, Y.; Wysocki, G.; Lewicki, R.; Tittel, F.K. Recent advances of laser-spectroscopy-based techniques for applications in breath analysis. J. Breath Res. 2007, doi:10.1088/1752-7155/1/1/014001.

148. Ramgir, N.S. Electronic nose based on nanomaterials: Issues, challenges, and prospects. ISRN Nanomat. 2013, 2013, 21.

149. Manginell, R.P.; Bauer, J.M.; Moorman, M.W.; Sanchez, L.J.; Anderson, J.M.; Whiting, J.J.; Porter, D.A.; Copic, D.; Achyuthan, K.E. A monolithically-integrated mugc chemical sensor system. Sensors 2011, 11, 6517-6532.

150. Liu, J.; Seo, J.H.; Li, Y.; Chen, D.; Kurabayashi, K.; Fan, X. Smart multi-channel two-dimensional micro-gas chromatography for rapid workplace hazardous volatile organic compounds measurement. Lab. Chip 2013, 13, 818-825. 
151. Sun, J.H.; Cui, D.F.; Chen, X.; Zhang, L.L.; Cai, H.Y.; Li, H. A micro gas chromatography column with a micro thermal conductivity detector for volatile organic compound analysis. Rev. Sci. Instrum. 2013, doi:10.1063/1.4789526.

152. Fung, A.O.; Mykhaylova, N. Analysis of airborne biomarkers for point-of-care diagnostics. J. Lab. Autom. 2014, 19, 225-247.

153. Queralto, N.; Berliner, A.N.; Goldsmith, B.; Martino, R.; Rhodes, P.; Lim, S.H. Detecting cancer by breath volatile organic compound analysis: A review of array-based sensors. J. Breath Res. 2014, doi:10.1088/1752-7155/8/2/027112.

154. Miekisch, W.; Schubert, J.K.; Noeldge-Schomburg, G.F. Diagnostic potential of breath analysis focus on volatile organic compounds. Clin. Chim. Acta 2004, 347, 25-39.

155. Aghdassi, E.; Allard, J.P. Breath alkanes as a marker of oxidative stress in different clinical conditions. Free Radic. Biol. Med. 2000, 28, 880-886.

156. Kneepkens, C.M.; Lepage, G.; Roy, C.C. The potential of the hydrocarbon breath test as a measure of lipid peroxidation. Free Radic. Biol. Med. 1994, 17, 127-160.

157. Allerheiligen, S.R.; Ludden, T.M.; Burk, R.F. The pharmacokinetics of pentane, a by-product of lipid peroxidation. Drug Metab. Dispos. 1987, 15, 794-800.

158. Dryahina, K.; Spanel, P.; Pospisilova, V.; Sovova, K.; Hrdlicka, L.; Machkova, N.; Lukas, M.; Smith, D. Quantification of pentane in exhaled breath, a potential biomarker of bowel disease, using selected ion flow tube mass spectrometry. Rapid Commun. Mass Spectrom. 2013, 27, 1983-1992.

159. Risby, T.H.; Sehnert, S.S. Clinical application of breath biomarkers of oxidative stress status. Free Radic. Biol. Med. 1999, 27, 1182-1192.

160. Kohlmuller, D.; Kochen, W. Is n-pentane really an index of lipid peroxidation in humans and animals? A methodological reevaluation. Anal. Biochem. 1993, 210, 268-276.

161. Gelmont, D.; Stein, R.A.; Mead, J.F. Isoprene-the main hydrocarbon in human breath. Biochem. Biophys. Res. Commun. 1981, 99, 1456-1460.

162. Turner, C.; Spanel, P.; Smith, D. A longitudinal study of breath isoprene in healthy volunteers using selected ion flow tube mass spectrometry (SIFT-MS). Physiol. Meas. 2006, 27, 13-22.

163. Kushch, I.; Arendacka, B.; Stolc, S.; Mochalski, P.; Filipiak, W.; Schwarz, K.; Schwentner, L.; Schmid, A.; Dzien, A.; Lechleitner, M., et al. Breath isoprene-aspects of normal physiology related to age, gender and cholesterol profile as determined in a proton transfer reaction mass spectrometry study. Clin. Chem. Lab. Med. 2008, 46, 1011-1018.

164. Spanel, P.; Davies, S.; Smith, D. Quantification of breath isoprene using the selected ion flow tube mass spectrometric analytical method. Rapid Commun. Mass Spectrom. 1999, 13, 1733-1738.

165. Conkle, J.P.; Camp, B.J.; Welch, B.E. Trace composition of human respiratory gas. Arch. Environ. Health 1975, 30, 290-295.

166. DeMaster, E.G.; Nagasawa, H.T. Isoprene, an endogenous constituent of human alveolar air with a diurnal pattern of excretion. Life Sci. 1978, 22, 91-97.

167. Deneris, E.S.; Stein, R.A.; Mead, J.F. In vitro biosynthesis of isoprene from mevalonate utilizing a rat liver cytosolic fraction. Biochem. Biophys. Res. Commun. 1984, 123, 691-696.

168. Deneris, E.S.; Stein, R.A.; Mead, J.F. Acid-catalyzed formation of isoprene from a mevalonatederived product using a rat liver cytosolic fraction. J. Biol. Chem. 1985, 260, 1382-1385. 
169. Mendis, S.; Sobotka, P.A.; Euler, D.E. Pentane and isoprene in expired air from humans: Gas-chromatographic analysis of single breath. Clin. Chem. 1994, 40, 1485-1488.

170. Jones, A.W.; Lagesson, V.; Tagesson, C. Origins of breath isoprene. J. Clin. Pathol. 1995, 48, 979-980.

171. Larstad, M.A.; Toren, K.; Bake, B.; Olin, A.C. Determination of ethane, pentane and isoprene in exhaled air--effects of breath-holding, flow rate and purified air. Acta Physiol. (Oxf) 2007, 189, 87-98.

172. Stein, R.A.; Mead, J.F. Small hydrocarbons formed by the peroxidation of squalene. Chem. Phys. Lipids 1988, 46, 117-120.

173. Jones, P.J.; Schoeller, D.A. Evidence for diurnal periodicity in human cholesterol synthesis. J. Lipid Res. 1990, 31, 667-673.

174. Stone, B.G.; Besse, T.J.; Duane, W.C.; Evans, C.D.; DeMaster, E.G. Effect of regulating cholesterol biosynthesis on breath isoprene excretion in men. Lipids 1993, 28, 705-708.

175. Bach, T.J. Some new aspects of isoprenoid biosynthesis in plants - a review. Lipids 1995, 30, 191-202.

176. Silver, G.M.; Fall, R. Characterization of aspen isoprene synthase, an enzyme responsible for leaf isoprene emission to the atmosphere. J. Biol. Chem. 1995, 270, 13010-13016.

177. Hyspler, R.; Crhova, S.; Gasparic, J.; Zadak, Z.; Cizkova, M.; Balasova, V. Determination of isoprene in human expired breath using solid-phase microextraction and gas chromatography-mass spectrometry. J. Chromatogr. B 2000, 739, 183-190.

178. Beytia, E.D.; Porter, J.W. Biochemistry of polyisoprenoid biosynthesis. Annu. Rev. Biochem. 1976, 45, 113-142.

179. Lin, D.S.; Connor, W.E. The long term effects of dietary cholesterol upon the plasma lipids, lipoproteins, cholesterol absorption, and the sterol balance in man: The demonstration of feedback inhibition of cholesterol biosynthesis and increased bile acid excretion. J. Lipid Res. 1980, 21, 1042-1052.

180. Quintao, E.; Grundy, S.M.; Ahrens, E.H., Jr. Effects of dietary cholesterol on the regulation of total body cholesterol in man. J. Lipid Res. 1971, 12, 233-247.

181. King, J.; Kupferthaler, A.; Frauscher, B.; Hackner, H.; Unterkofler, K.; Teschl, G.; Hinterhuber, H.; Amann, A.; Högl, B. Measurement of endogenous acetone and isoprene in exhaled breath during sleep. Physiol. Meas. 2012, 33, 413.

182. Amann, A.; Miekisch, W.; Schubert, J.; Buszewski, B.; Ligor, T.; Jezierski, T.; Pleil, J.; Risby, T. Analysis of exhaled breath for disease detection. Annu. Rev. Anal. Chem. 2014, 7, 455-482.

183. Fuchs, D.; Jamnig, H.; Heininger, P.; Klieber, M.; Schroecksnadel, S.; Fiegl, M.; Hackl, M.; Denz, H.; Amann, A. Decline of exhaled isoprene in lung cancer patients correlates with immune activation. J. Breath Res. 2012, 6, 027101.

184. Rooth, G.; Ostenson, S. Acetone in alveolar air, and the control of diabetes. Lancet 1966, 2, 1102-1105.

185. Trotter, M.D.; Sulway, M.J.; Trotter, E. The rapid determination of acetone in breath and plasma. Clin. Chim. Acta 1971, 35, 137-143.

186. Manolis, A. The diagnostic potential of breath analysis. Clin. Chem. 1983, 29, 5-15. 
187. Hoell, D.; Mensing, T.; Roggenbuck, R.; Sakuth, M.; Sperlich, E.; Urban, T.; Neier, W.; Strehlke, G. 2-Butanone. In Ullmann's Encyclopedia of Industrial Chemistry; Wiley-VCH Verlag GmbH \& Co. KGaA: Weinheim, Germany, 2009; doi:10.1002/14356007.a04_475.pub2.

188. Jollivet, N.; Bézenger, M.-C.; Vayssier, Y.; Belin, J.-M. Production of volatile compounds in liquid cultures by six strains of coryneform bacteria. Appl. Microbiol. Biotechnol. 1992, 36, 790-794.

189. Ken, W. Volatile metabolites from actinomycetes. Chemosphere 1996, 32, 1427-1434.

190. Ron, W.; Christine, H.; Alan, B.; Andrzej, K. Effect of substrate composition on production of volatile organic compounds from trichoderma spp. Inhibitory to wood decay fungi. Int. Biodeterior. Biodegrad. 1997, 39, 199-205.

191. Farag, M.A.; Ryu, C.-M.M.; Sumner, L.W.; Paré, P.W. Gc-ms spme profiling of rhizobacterial volatiles reveals prospective inducers of growth promotion and induced systemic resistance in plants. Phytochemistry 2006, 67, 2262-2268.

192. Yoneda, H.; Tantillo, D.J.; Atsumi, S. Biological production of 2-butanone in escherichia coli. ChemSusChem 2014, 7, 92-95.

193. Min, K.; Kim, S.; Yum, T.; Kim, Y.; Sang, B.I.; Um, Y. Conversion of levulinic acid to 2-butanone by acetoacetate decarboxylase from clostridium acetobutylicum. Appl. Microbiol. Biotechnol. 2013, 97, 5627-5634.

194. Oomah, B.D.; Razafindrainibe, M.; Drover, J.C. Headspace volatile components of canadian grown low-tannin faba bean (vicia faba 1.) genotypes. J. Sci. Food Agric. 2014, 94, 473-481.

195. Song, G.C.; Ryu, C.M. Two volatile organic compounds trigger plant self-defense against a bacterial pathogen and a sucking insect in cucumber under open field conditions. Int. J. Mol. Sci. 2013, 14, 9803-9819.

196. Mochalski, P.; King, J.; Unterkofler, K.; Hinterhuber, H.; Amann, A. Emission rates of selected volatile organic compounds from skin of healthy volunteers. J. Chromatogr. B 2014, 959, 62-70.

197. Rudnicka, J.; Mochalski, P.; Agapiou, A.; Statheropoulos, M.; Amann, A.; Buszewski, B. Application of ion mobility spectrometry for the detection of human urine. Anal. Bioanal. Chem. 2010, 398, 2031-2038.

198. De Lacy Costello, B.; Amann, A.; Al-Kateb, H.; Flynn, C.; Filipiak, W.; Khalid, T.; Osborne, D.; Ratcliffe, N.M. A review of the volatiles from the healthy human body. J. Breath Res. 2014, 8, doi:10.1088/1752-7155/8/1/014001.

199. Amann, A.; Costello Bde, L.; Miekisch, W.; Schubert, J.; Buszewski, B.; Pleil, J.; Ratcliffe, N.; Risby, T. The human volatilome: Volatile organic compounds (VOCs) in exhaled breath, skin emanations, urine, feces and saliva. J. Breath Res. 2014, 8, doi:10.1088/1752-7155/8/3/034001.

200. Buszewski, B.; Ulanowska, A.; Kowalkowski, T.; Cieslinski, K. Investigation of lung cancer biomarkers by hyphenated separation techniques and chemometrics. Clin. Chem. Lab. Med. 2012, 50, 573-581.

201. Ligor, M.; Ligor, T.; Bajtarevic, A.; Ager, C.; Pienz, M.; Klieber, M.; Denz, H.; Fiegl, M.; Hilbe, W.; Weiss, W. Determination of volatile organic compounds in exhaled breath of patients with lung cancer using solid phase microextraction and gas chromatography mass spectrometry. Clin. Chem. Lab. Med. 2009, 47, 550-560.

202. Amal, H.; Shi, D.Y.; Ionescu, R.; Zhang, W.; Hua, Q.L.; Pan, Y.Y.; Tao, L.; Liu, H.; Haick, H. Assessment of ovarian cancer conditions from exhaled breath. Int. J. Cancer 2014. 
203. Ulanowska, A.; Kowalkowski, T.; Hrynkiewicz, K.; Jackowski, M.; Buszewski, B. Determination of volatile organic compounds in human breath for helicobacter pylori detection by SPME-GC/MS. Biomed. Chromatogr. 2011, 25, 391-397.

204. Bos, L.D.; Sterk, P.J.; Schultz, M.J. Volatile metabolites of pathogens: A systematic review. PLoS Pathog. 2013, 9, e1003311.

205. Barnes, P.J.; Belvisi, M.G. Nitric oxide and lung disease. Thorax 1993, 48, 1034-1043.

206. Stryer, L. Biochemistry, 4th ed.; W.H. Freeman and Company: New York, NY, USA, 1995.

207. Ricciardolo, F.L.M. Multiple roles of nitric oxide in the airways. Thorax 2003, 58, 175-182.

208. Kamijo, R.; Gerecitano, J.; Shapiro, D.; Green, S.J.; Aguet, M.; Le, J.; Vilcek, J. Generation of nitric oxide and clearance of interferon-gamma after bcg infection are impaired in mice that lack the interferon-gamma receptor. J. Inflamm. 1995, 46, 23-31.

209. Green, S.J.; Nacy, C.A.; Schreiber, R.D.; Granger, D.L.; Crawford, R.M.; Meltzer, M.S.; Fortier, A.H. Neutralization of gamma interferon and tumor necrosis factor alpha blocks in vivo synthesis of nitrogen oxides from l-arginine and protection against francisella tularensis infection in mycobacterium bovis bcg-treated mice. Infect. Immun. 1993, 61, 689-698.

210. Green, S.J.; Mellouk, S.; Hoffman, S.L.; Meltzer, M.S.; Nacy, C.A. Cellular mechanisms of nonspecific immunity to intracellular infection: Cytokine-induced synthesis of toxic nitrogen oxides from l-arginine by macrophages and hepatocytes. Immunol. Lett. 1990, 25, 15-19.

211. Green, S.J.; Scheller, L.F.; Marletta, M.A.; Seguin, M.C.; Klotz, F.W.; Slayter, M.; Nelson, B.J.; Nacy, C.A. Nitric oxide: Cytokine-regulation of nitric oxide in host resistance to intracellular pathogens. Immunol. Lett. 1994, 43, 87-94.

212. Ghosh, S.; Erzurum, S.C. Nitric oxide metabolism in asthma pathophysiology. Biochim. Biophys. Acta 2011, 1810, 1008-1016.

213. Bucca, C.; Cicolin, A.; Guida, G.; Heffler, E.; Brussino, L.; Rolla, G. Exhaled nitric oxide (feno) in non-pulmonary diseases. J. Breath Res. 2012, doi:10.1088/1752-7155/6/2/027104.

214. Dweik, R.A.; Boggs, P.B.; Erzurum, S.C.; Irvin, C.G.; Leigh, M.W.; Lundberg, J.O.; Olin, A.C.; Plummer, A.L.; Taylor, D.R. An official ats clinical practice guideline: Interpretation of exhaled nitric oxide levels (FENO) for clinical applications. Am. J. Respir. Crit. Care. Med. 2011, 184, $602-615$.

215. Leung, T.F.; Ko, F.W.; Wong, G.W. Recent advances in asthma biomarker research. Ther. Adv. Respir. Dis. 2013, 7, 297-308.

216. Ricciardolo, F.L. Revisiting the role of exhaled nitric oxide in asthma. Curr. Opin. Pulm. Med. 2014, 20, 53-59.

217. Ludviksdottir, D.; Diamant, Z.; Alving, K.; Bjermer, L.; Malinovschi, A. Clinical aspects of using exhaled no in asthma diagnosis and management. Clin. Respir. J. 2012, 6, 193-207.

218. Price, D.; Ryan, D.; Burden, A.; Von Ziegenweidt, J.; Gould, S.; Freeman, D.; Gruffydd-Jones, K.; Copland, A.; Godley, C.; Chisholm, A., et al. Using fractional exhaled nitric oxide (feno) to diagnose steroid-responsive disease and guide asthma management in routine care. Clin. Transl. Allergy 2013, doi:10.1186/2045-7022-3-37.

219. Taylor, D.R. Advances in the clinical applications of exhaled nitric oxide measurements. J. Breath Res. 2012, doi:10.1088/1752-7155/6/4/047102. 
220. Mandon, J.; Hogman, M.; Merkus, P.J.; van Amsterdam, J.; Harren, F.J.; Cristescu, S.M. Exhaled nitric oxide monitoring by quantum cascade laser: Comparison with chemiluminescent and electrochemical sensors. J. Biomed. Opt. 2012, doi:10.1117/1.jbo.17.1.017003.

221. Kim, S.H.; Moon, J.Y.; Kwak, H.J.; Kim, S.I.; Park, D.W.; Kim, J.W.; Kim, T.H.; Sohn, J.W.; Shin, D.H.; Park, S.S., et al. Comparison of two exhaled nitric oxide analyzers: The niox mino hand-held electrochemical analyzer and the noa280i stationary chemiluminescence analyzer. Respirology 2012, 17, 830-834.

222. Hillas, G.; Loukides, S.; Kostikas, K.; Bakakos, P. Biomarkers obtained by non-invasive methods in patients with copd: Where do we stand, what do we expect? Curr. Med. Chem. 2009, 16, 2824-2838.

223. Bessa, V.; Tseliou, E.; Bakakos, P.; Loukides, S. Noninvasive evaluation of airway inflammation in asthmatic patients who smoke: Implications for application in clinical practice. Ann. Allergy Asthma Immunol. 2008, 101, 226-232; quiz 232-224, 278.

224. Grasemann, H.; Ioannidis, I.; Tomkiewicz, R.P.; de Groot, H.; Rubin, B.K.; Ratjen, F. Nitric oxide metabolites in cystic fibrosis lung disease. Arch. Dis. Child. 1998, 78, 49-53.

225. Hogman, M. Extended no analysis in health and disease. J. Breath Res. 2012, 6, doi:10.1088/1752-7155/6/4/047103.

226. Fisher, A.J.; Gabbay, E.; Small, T.; Doig, S.; Dark, J.H.; Corris, P.A. Cross sectional study of exhaled nitric oxide levels following lung transplantation. Thorax 1998, 53, 454-458.

227. Baylis, C. Nitric oxide deficiency in chronic kidney disease. Am. J. Phys. Renal Phys. 2008, 294, F1-F9.

228. Huang, Y.; Lemberg, D.A.; Day, A.S.; Dixon, B.; Leach, S.; Bujanover, Y.; Jaffe, A.; Thomas, P.S. Markers of inflammation in the breath in paediatric inflammatory bowel disease. J. Pediatr Gastroenterol Nutr. 2014, 59, 505-510

229. Davies, S.; Spanel, P.; Smith, D. Quantitative analysis of ammonia on the breath of patients in endstage renal failure. Kidney Int. 1997, 52, 223-228.

230. Li, M.; Ding, J.; Gu, H.; Zhang, Y.; Pan, S.; Xu, N.; Chen, H.; Li, H. Facilitated diffusion of acetonitrile revealed by quantitative breath analysis using extractive electrospray ionization mass spectrometry. Sci Rep. 2013, 3, 1205.

231. Greenberg, M. Toxicological review of acetonitrile; U.S. Environmental Protection Agency: Washington, DC, 1999.

232. Rahman, I.; van Schadewijk, A.A.; Crowther, A.J.; Hiemstra, P.S.; Stolk, J.; MacNee, W.; De Boer, W.I. 4-hydroxy-2-nonenal, a specific lipid peroxidation product, is elevated in lungs of patients with chronic obstructive pulmonary disease. Am. J. Respir. Crit. Care. Med. 2002, 166, 490-495.

233. Marchitti, S.A.; Brocker, C.; Stagos, D.; Vasiliou, V. Non-p450 aldehyde oxidizing enzymes: The aldehyde dehydrogenase superfamily. Expert Opin Drug Metab Toxicol 2008, 4, 697-720.

234. O'Brien, P.J.; Siraki, A.G.; Shangari, N. Aldehyde sources, metabolism, molecular toxicity mechanisms, and possible effects on human health. Crit. Rev. Toxicol. 2005, 35, 609-662.

235. Vaz, A.D.; Coon, M.J. Hydrocarbon formation in the reductive cleavage of hydroperoxides by cytochrome p-450. Proc. Natl. Acad. Sci. USA. 1987, 84, 1172-1176. 
236. Branton, P.J.; McAdam, K.G.; Winter, D.B.; Liu, C.; Duke, M.G.; Proctor, C.J. Reduction of aldehydes and hydrogen cyanide yields in mainstream cigarette smoke using an amine functionalised ion exchange resin. Chem. Cent. J. 2011, doi:10.1186/1752-153x-5-15.

237. Ahotupa, M.; Bussacchini-Griot, V.; Bereziat, J.C.; Camus, A.M.; Bartsch, H. Rapid oxidative stress induced by n-nitrosamines. Biochem. Biophys. Res. Commun. 1987, 146, 1047-1054.

238. Schrader, E.; Hirsch-Ernst, K.I.; Scholz, E.; Kahl, G.F.; Foth, H. Metabolism of 4(methylnitrosamino)-1-(3-pyridyl)-1-butanone (nnk) in primary cultures of rat alveolar type ii cells. Drug Metab. Dispos. 2000, 28, 180-185.

239. Hecht, S.S. Recent studies on mechanisms of bioactivation and detoxification of 4(methylnitrosamino)-1-(3-pyridyl)-1-butanone (nnk), a tobacco-specific lung carcinogen. Crit. Rev. Toxicol. 1996, 26, 163-181.

240. Akopyan, G.; Bonavida, B. Understanding tobacco smoke carcinogen nnk and lung tumorigenesis. Int. J. Oncol. 2006, 29, 745-752.

241. Byrne, G.I.; Lehmann, L.K.; Kirschbaum, J.G.; Borden, E.C.; Lee, C.M.; Brown, R.R. Induction of tryptophan degradation in vitro and in vivo: A gamma-interferon-stimulated activity. $J$. Interferon Res. 1986, 6, 389-396.

242. Brandacher, G.; Perathoner, A.; Ladurner, R.; Schneeberger, S.; Obrist, P.; Winkler, C.; Werner, E.R.; Werner-Felmayer, G.; Weiss, H.G.; Gobel, G., et al. Prognostic value of indoleamine 2,3dioxygenase expression in colorectal cancer: Effect on tumor-infiltrating t cells. Clin Cancer Res. 2006, 12, 1144-1151.

243. Brandacher, G.; Winkler, C.; Schroecksnadel, K.; Margreiter, R.; Fuchs, D. Antitumoral activity of interferon-gamma involved in impaired immune function in cancer patients. Curr. Drug Metab. 2006, 7, 599-612.

244. Deng, C.; Zhang, X.; Li, N. Investigation of volatile biomarkers in lung cancer blood using solidphase microextraction and capillary gas chromatography-mass spectrometry. J. Chromatogr. B 2004, 808, 269-277.

245. Taivans, I.; Bukovskis, M.; Strazda, G.; Jurka, N. Breath testing as a method for detecting lung cancer. Expert Rev. Anticancer Ther. 2014, 14, 121-123.

246. Dent, A.G.; Sutedja, T.G.; Zimmerman, P.V. Exhaled breath analysis for lung cancer. J. Thorac. Dis. 2013, 5, S540-s550.

247. De Boer, N.K.; de Meij, T.G.; Oort, F.A.; Ben Larbi, I.; Mulder, C.J.; van Bodegraven, A.A.; van der Schee, M.P. The scent of colorectal cancer: Detection by volatile organic compound analysis. Clin. Gastroenterol. Hepatol. 2014, 12, 1085-1089.

248. Siegel, R.; Naishadham, D.; Jemal, A. Cancer statistics, 2012. CA Cancer J. Clin 2012, 62, 10-29.

249. Patel, K.; Davis, S.D.; Johnson, R.; Esther, C.R., Jr. Exhaled breath condensate purines correlate with lung function in infants and preschoolers. Pediatr Pulmonol 2013, 48, 182-187.

250. Marco, S. The need for external validation in machine olfaction: Emphasis on health-related applications. Anal. Bioanal. Chem. 2014, 406, 3941-3956.

251. Broadhurst, D.I.; Kell, D.B. Statistical strategies for avoiding false discoveries in metabolomics and related experiments. Metabolomics 2006, 2, 171-196. 
252. Smolinska, A.; Hauschild, A.-C.; Fijten, R.; Dallinga, J.; Baumbach, J.; van Schooten, F. Current breathomics-a review on data pre-processing techniques and machine learning in metabolomics breath analysis. J. Breath Res. 2014, doi:10.1088/1752-7155/8/2/027105.

253. Miekisch, W.; Herbig, J.; Schubert, J.K. Data interpretation in breath biomarker research: Pitfalls and directions. J. Breath Res. 2012, 6, 036007.

254. Malley, J.D.; Dasgupta, A.; Moore, J.H. The limits of $p$-values for biological data mining. BioData Mining 2013, doi:10.1186/1756-0381-6-10.

255. Nguyen, H.T.; Jia, G.; Shah, Z.K.; Pohar, K.; Mortazavi, A.; Zynger, D.L.; Wei, L.; Yang, X.; Clark, D.; Knopp, M.V. Prediction of chemotherapeutic response in bladder cancer using K-means clustering of dynamic contrast-enhanced (DCE)-MRI pharmacokinetic parameters. $J$. Magn. Reson. Imag. 2014, doi:10.1002/jmri.24663.

256. Dutta, R.; Kashwan, K.R.; Bhuyan, M.; Hines, E.L.; Gardner, J.W. Electronic nose based tea quality standardization. Neural Netw. 2003, 16, 847-853.

257. Von Luxburg, U. A tutorial on spectral clustering. Statist. Comput. 2007, 17, 395-416.

258. Krzanowski, W.J. Principles of Multivariate Analysis: A User's Perspective; (Oxford Statistical Science Series;) Oxford University Press: Oxford, UK, 2000.

259. Boots, A.W.; van Berkel, J.J.; Dallinga, J.W.; Smolinska, A.; Wouters, E.F.; van Schooten, F.J. The versatile use of exhaled volatile organic compounds in human health and disease. J. Breath Res. 2012, 6, 027108.

260. Wold, S.; Sjöström, M.; Eriksson, L. Pls-regression: A basic tool of chemometrics. Chemom. Intell. Lab. Syst. 2001, 58, 109-130.

261. Szymańska, E.; Saccenti, E.; Smilde, A.; Westerhuis, J. Double-check: Validation of diagnostic statistics for pls-da models in metabolomics studies. Metabolomics 2012, 8, 3-16.

262. Westerhuis, J.a.; Hoefsloot, H.C.J.; Smit, S.; Vis, D.J.; Smilde, A.K.; Velzen, E.J.J.; Duijnhoven, J.P.M.; Dorsten, F.A. Assessment of plsda cross validation. Metabolomics 2008, 4, 81-89.

263. Mahadevan, S.; Shah, S.L.; Marrie, T.J.; Slupsky, C.M. Analysis of metabolomic data using support vector machines. Anal. Chem. 2008, 80, 7562-7570.

264. Amato, F.; López, A.; Peña-Méndez, E.M.; Vaňhara, P.; Hampl, A.; Havel, J. Artificial neural networks in medical diagnosis. J. Appl. Biomed. 2013, 11, 47-58.

265. Taylor, J.; King, R.D.; Altmann, T.; Fiehn, O. Application of metabolomics to plant genotype discrimination using statistics and machine learning. 2002, 18, 241-248.

266. Smolinska, A.; Blanchet, L.; Coulier, L.; Ampt, K.A.M.; Luider, T.; Hintzen, R.Q.; Wijmenga, S.S.; Buydens, L.M.C. Interpretation and visualization of non-linear data fusion in kernel space: Study on metabolomic characterization of progression of multiple sclerosis. PLoS One 2012, 7, e38163.

267. Krooshof, P.W.T.; Üstün, B.; Postma, G.J.; Buydens, L.M.C. Visualization and recovery of the (bio)chemical interesting variables in data analysis with support vector machine classification. Anal. Chem. 2010, 82, 7000-7007.

268. Shaffer, R.E.; Rose-Pehrsson, S.L.; McGill, R.A. A comparison study of chemical sensor array pattern recognition algorithms. Anal. Chim. Acta 1999, 384, 305-317.

269. Sung, J.; Wang, Y.; Chandrasekaran, S.; Witten, D.M.; Price, N.D. Molecular signatures from omics data: From chaos to consensus. Biotechnol. J. 2012, 7, 946-957. 
270. Xia, J.; Broadhurst, D.I.; Wilson, M.; Wishart, D.S. Translational biomarker discovery in clinical metabolomics: An introductory tutorial. Metabolomics 2013, 9, 280-299.

271. STARD Statement. Available online: http://www.stard-statement.org (accessed on 25 September 2014).

272. McShane, L.; Cavenagh, M.; Lively, T.; Eberhard, D.; Bigbee, W.; Williams, P.; Mesirov, J.; Polley, M.-Y.; Kim, K.; Tricoli, J., et al. Criteria for the use of omics-based predictors in clinical trials: Explanation and elaboration. BMC Med. 2013, doi:10.1186/1741-7015-11-220.

273. Bossuyt, P.M.; Reitsma, J.B.; Bruns, D.E.; Gatsonis, C.A.; Glasziou, P.P.; Irwig, L.M.; Lijmer, J.G.; Moher, D.; Rennie, D.; de Vet, H.C.W. Towards complete and accurate reporting of studies of diagnostic accuracy: The stard initiative. Clin. Chem. Lab. Med. 2003, 326, 41-44.

274. Cunha, M.G.; Hoenigman, S.; Kanchagar, C.; Rearden, P.; Sassetti, C.S.; Trevejo, J.M.; Keshava, N. Joint analysis of differential mobility spectrometer and mass spectrometer features for tuberculosis biomarkers. Conf Proc. IEEE Eng. Med. Biol Soc. 2008, 2008, 359-362.

275. Wishart, D.S.; Knox, C.; Guo, A.C.; Eisner, R.; Young, N.; Gautam, B.; Hau, D.D.; Psychogios, N.; Dong, E.; Bouatra, S., et al. Hmdb: A knowledgebase for the human metabolome. Nucleic Acids Res. 2009, 37, D603-D610.

276. Halling-Brown, M.D.; Bulusu, K.C.; Patel, M.; Tym, J.E.; Al-Lazikani, B. Cansar: An integrated cancer public translational research and drug discovery resource. Nucleic Acids Res. 2012, 40, D947-D956.

277. Liu, Q.; Wu, C.; Cai, H.; Hu, N.; Zhou, J.; Wang, P. Cell-based biosensors and their application in biomedicine. Chem Rev. 2014, 114, 6423-6461.

278. Liu, Y.; Dong, X.; Chen, P. Biological and chemical sensors based on graphene materials. Chem. Soc. Rev. 2012, 41, 2283-2307.

(C) 2015 by the authors; licensee MDPI, Basel, Switzerland. This article is an open access article distributed under the terms and conditions of the Creative Commons Attribution license (http://creativecommons.org/licenses/by/4.0/). 